\title{
Intragenerational redistribution in a funded pension system*
}

\author{
BENEDETTA FRASSI \\ AXES Research Unit, IMT School for Advanced Studies Lucca, Lucca, Italy \\ GIORGIO GNECCO \\ AXES Research Unit, IMT School for Advanced Studies Lucca, Lucca, Italy \\ (e-mail: giorgio.gnecco@imtlucca.it) \\ FABIO PAMMOLLI \\ Polytechnic University of Milan, Department of Management Engineering, and CADS, \\ Human Technopole, Milan, Italy \\ XUE WEN \\ AXES Research Unit, IMT School for Advanced Studies Lucca, Lucca, Italy
}

\begin{abstract}
In a general equilibrium framework, this paper studies the properties, in terms of labour market distortions and capital accumulation, of three social security systems: a pay-as-yougo notional defined contribution (PAYG NDC), a fully funded (FF), and a novel modified FF (MFF) system, which includes an intragenerational redistributive component to guarantee minimum living standards to future low-income retirees. We show that while PAYG NDC depresses labour supply and physical capital accumulation, FF is neutral on both dimensions. Conversely, MFF slightly increases physical capital accumulation, without significantly reducing labour supply incentives. Moreover, it reduces the burden of future intergenerational redistribution, and increases social welfare.
\end{abstract}

Keywords: Pension systems, endogenous labour supply, capital accumulation, redistribution.

\section{Introduction}

Several OECD countries are currently facing a remarkable ageing process, which is driven by increases in life expectancy and declines in fertility rates (OECD, 2014, 2015). The observed increases in the median age of the population, which is projected to continue raising over the years ahead, have resulted in an increase in the

* The authors acknowledge support from the Italian National Interest Project'Crisis Lab' (MIUR, PNR 2011-2013). 
demographic old-age dependency ratio. ${ }^{1}$ According to OECD (2015), the demographic old-age dependency ratio, equal to 14 in 1950, reached the value of 28 in 2015 , and it is projected to nearly double in 2075, reaching the value of 55 .

The increase in the demographic old-age dependency ratio should be seriously taken into account by governments that are financing public pensions via a pay-as-you-go (PAYG) system. In a PAYG system, those who are currently occupied finance the pensions of same-period retirees, based on the promise that they will receive a similar treatment by future cohorts of workers. Due to this mechanism, a decline in population growth may jeopardize the financial viability of the system itself, since it reduces the likelihood that the promise can be maintained in the future. ${ }^{2}$ In the short term, OECD countries providing PAYG-financed public pensions will suffer from the retirement of the Baby Boom generation, a cohort much larger than the ones that followed in the workforce. ${ }^{3}$

According to World Bank (2005), traditional strategies adopted in order to make public pension promises more affordable within a PAYG system, i.e., adjustments in the pension eligibility age, in indexation arrangements, and in benefits' accrual rates, have often been unsatisfactory.

In search for sustainability, some countries (e.g., Italy and Sweden) have introduced the so-called notional defined contribution (NDC) scheme. By maintaining PAYG, the NDC plan provides benefits that bear an actuarial relationship to individual lifetime contributions. ${ }^{4}$ Nevertheless, due to demographic changes, the introduction of NDC can only partially ease PAYG system's sustainability tensions.

Therefore, in a context of falling fertility and rising longevity, one should seriously consider not merely an amendment of the system, but its replacement with a different and more sustainable one.

The most credited solution to the solvency problem originated by the PAYG system in an ageing economy is the privatization of social security, i.e., the shift from the PAYG to the fully funded (FF) system, where each individual builds up her own pension by contributing to a personal account. ${ }^{5}$ It is well known that, in an ageing economy, the FF system boosts higher physical capital accumulation than the PAYG system, therefore leads to higher economic growth. ${ }^{6}$ Indeed, an argument often made in favour of the FF system is that it would accumulate a higher increase in national savings than the one that would occur within the PAYG system. However, the adoption of a FF system does not come without disadvantages (such as the

1 The demographic old-age dependency ratio is defined as the number of individuals aged 65 and over per 100 people of working age, defined as those aged between 20 and 64 (OECD, 2015).

2 According to Samuelson (1958), Aaron (1966) and Samuelson (1975), the PAYG system, defined as the 'social contract' between generations, is desirable only when each generation maintains positive real rates of return on contributions, which happens so long as real earnings growth and population growth remain positive.

3 See also Schwarz et al. (2014) for a discussion about difficulties encountered by current pension systems in Europe and Central Asia, which are due to recent demographic challenges such as ageing.

4 See, for example, Disney (1999), Holzmann and Palmer (2006), and World Bank (2005).

${ }^{5}$ We refer to FF defined contribution schemes where the post-retirement consumption, given life expectancy and the interest rate, is determined only by the amount of contributions paid into the fund. In an ageing economy, the FF defined benefit scheme, which pre-commits to pay a defined pension benefit no matter on the value of assets accumulated, runs the solvency risk (OECD, 2014).

6 See, for example, Docquier and Paddison (2003). 
transition cost to the FF system itself ${ }^{7}$ ), and for this reason there is no common opinion in the literature on whether PAYG systems should be entirely replaced by FF systems. ${ }^{8}$

In addition to the financial viability of the pension system, which has become of a primary importance, any social welfare programme has to guarantee an adequate standard of living in retirement (OECD (2014)).${ }^{9}$ In this respect, the FF system is able to improve financial sustainability but, due to its working mechanism and contrarily to unfunded schemes, it does not guarantee poverty relief and redistribution, ${ }^{10}$ which are two of the most important objectives pursued by social security systems. ${ }^{11}$ While financially unsustainable, the PAYG system is designed to ensure an adequate income throughout retirement by including different types of redistribution, namely the intergenerational and the intragenerational one. ${ }^{12}$ The former redistributes resources across generations (e.g., a reduction in the contribution rate of current workers implies an increase in contributions paid by future generations or a decrease in the amount of their pension benefits). The latter, instead, allocates resources across different income levels within the same generation (e.g., by guaranteeing a higher replacement rate to low-income earners). Similarly, the NDC, by maintaining PAYG, provides intergenerational redistribution and also very slight forms of withincohort redistribution, namely the one from men to women, the one achieved through survivor benefits, and the one obtained through credits for periods spent out of the paid labour force. ${ }^{13}$

In the attempt to overcome the solvency problems induced by PAYG, and to pursue the objective of retirement-income adequacy unmet by the FF, we introduce a modified version of the pure FF, which incorporates an intragenerational redistributive component. In particular, we study the possible advantages of a funded pension system that is able to produce an intragenerational redistribution across individuals with different economic availability.

To analyse the possible advantages of the newly proposed version of FF, which we call modified FF (MFF), we develop a general equilibrium two-period overlapping

${ }^{7}$ For a discussion of this transition cost (which can leave some future generations worse off than they would have been without the transition), see, for example, Chapter 17 in Heijdra (2003).

8 Among others, see Feldstein (2005), Feldstein and Samwick (1998), Kotlikoff (1996, 1998) and, for a different view, Breyer (1989) and Homburg (1990). Moreover, see Sinn (2000) for a general comparison between funded and unfunded systems.

${ }^{9}$ In connection to this issue, it is worth mentioning that, according to Schwarz et al. (2014), even the earliest pension schemes (starting from the seminal Bismarck's pension scheme adopted in 1889) were designed to cope with the risk of old-age poverty, at least for certain categories of workers (e.g., industrial workers with low-to-middle income). However, such models could not ensure full protection against poverty. For this reason, they were later complemented by additional features such as the provision of a minimum income to workers who made social security contribution only for short periods and to individuals who were not able to make contribution while young. In fact, today's pensions in OECD includes both basic and minimum pension (OECD, 2015).

10 Blake (2006) argues that even the FF provides slight forms of redistribution. In defined benefit plans early leavers subsidize long stayers, while in defined contribution schemes poor people subsidize rich people, and (if there is a unisex annuity rate) men subsidize women.

11 See Barr and Diamond (2006).

12 See Disney (1996) and Ignacio Conde-Ruiz and Profeta (2007).

13 According to World Bank (2005), the redistribution from men to women arises from the use of unisex annuity factors even though women tend to live longer. Conversely, the redistribution via survivor benefits occurs because annuity factors do not include the number and age of dependents. 
generations (OLG) model, where individuals decide how much to work and how much to save for old-age consumption. The returns to private savings and wages are determined by the profit maximizing behaviour of a firm with standard CobbDouglas production function. Since a representative agent framework does not capture intragenerational redistribution, we present a model with two productivity types. Differences in the skill level (and thus in the income level) among workers translate into differences in the magnitude of capital accumulation and labour supply distortion.

According to our results, the unfunded system generates labour supply distortions and depresses physical capital accumulation. More precisely, in the numerical investigation of the theoretical model we propose, the labour distortion in the PAYG NDC arises from government's decision to revaluate workers' contributions at a rate that is lower than the market interest rate. ${ }^{14}$ Therefore, by offering a lower amount of labour, the individual depresses her income and her savings. At the equilibrium, this reduction in saving causes the aggregate capital stock to fall. Conversely, the FF system depresses neither labour supply nor capital accumulation, since individuals recognize that contributions paid during the entire working career are a form of private savings.

We find that the intragenerational redistribution carried out in the MFF system slightly increases physical capital accumulation with respect to the pure FF case, without significantly reducing labour supply incentives. Moreover, in the range of parameter values examined, the MFF increases the social welfare with respect to both unfunded and pure funded schemes.

Therefore, the proposed MFF system, with its redistribution share aimed at guaranteeing minimum living standards to low-income individuals, seems to be a good compromise to pursue the objectives of reducing labour supply distortions, enhancing physical capital accumulation, and increasing social welfare. For all these reasons, the MFF is preferable to both the FF and the PAYG NDC schemes.

The paper is organized as follows. The model is presented in Section 2. Section 3 provides the closed economy general equilibrium analysis alongside the main analytical findings. Section 4 supports the analysis with a numerical investigation, and Section 5 provides conclusions. Further details are given in the Appendix.

\section{The model}

We present a two-period OLG model à la Diamond (1965) with endogenous labour supply to study the impact of different pension schemes. ${ }^{15} \mathrm{We}$ consider a PAYG NDC in opposition to a MFF scheme, i.e., a funded system that embodies a redistributive component. We consider a closed economy, where firms produce a single

${ }^{14}$ Even though the capital stock in the balanced growth path of the Diamond (1965) model may exceed the golden-rule level, implying a dynamically inefficient economy, the realistic parameter values we chose in our numerical simulation ensure that the interest rate is always greater than the PAYG NDC returns, implying a dynamically efficient economy.

15 See also Breyer and Straub (1993) and Sommacal (2006). 
homogenous good which can be used for both consumption and investment. Moreover, capital and labour are used as inputs in a constant returns CobbDouglas technology. Finally, individuals differ in their skill level.

In Section 2.1, we present individuals' optimal saving and labour supply decisions, and in Section 2.2, we illustrate the production function of the economy. Lastly, in Section 2.3, we analyse the public budget constraint under the two aforementioned pension systems.

\subsection{Households decisions}

In our OLG setting, people work in the first period of their life and retire in the second. As usual, the population growth rate is equal to $N_{t+1} / N_{t}=1+\rho_{t+1}$ with $\rho_{t+1}>-1$, where $N_{t}$ denotes the population at time $t$. Moreover, by assuming that generations are nonaltruistic we rule out bequests. Individuals differ in their productivity level $h_{i}$ which can be either high or low, ${ }^{16}$ i.e., $i=\{H, L\}$. In particular, we assume that a fixed fraction $\lambda_{L} \in(0,1)$ of the total population belongs to the low-skilled class, while the other fixed fraction $\lambda_{H}=1-\lambda_{L}$ belongs to the high-skilled class. The income level of an individual $i$ in her working period $t\left(y_{i, t}\right)$ is equal to $w_{t} h_{i} l_{i, t}$, where $w_{t}$ is the wage rate per efficient unit of labour, and $l_{i, t}$ is the labour supply provided in the same working period by an individual of type $i$. In our analysis, it is assumed that $0<h_{L}<h_{H}$. Both types of individuals contribute to the pension system when young, and receive pension benefits when retired. The pension contribution rate is exogenous, and equal to $\tau$, where $0<\tau<1$.

We formulate the individual maximization problem in the following form, taking a convenient and quite standard specification of the utility function to get a closed-form optimal solution:

$$
\begin{gathered}
\max _{l_{i, t}, s_{i, t}, c_{i, t}, c_{i, t+1}} U_{i, t}=\ln \left(c_{i, t}-\frac{l_{i, t}^{2}}{2}\right)+\beta \ln c_{i, t+1}, \\
\text { s.t. } \quad c_{i, t}+s_{i, t}=(1-\tau) w_{t} h_{i} l_{i, t}, \\
\text { s.t. } \quad c_{i, t+1}=R_{t+1} s_{i, t}+p_{i, t+1} .
\end{gathered}
$$

In the first period, the young working generations allocate their after tax wage income $(1-\tau) w_{t} h_{i} l_{i, t}$ between consumption $c_{i, t}$ and savings $s_{i, t}$. The old retired generation receives their previous savings $s_{i, t}$ plus the return $r_{t+1}$, where $R_{t+1}=1+r_{t+1}$, and a retirement benefit $p_{i, t+1}$, which depends on the pension system in force. The parameter $\beta \in$ $[0,1]$ represents the preference for future consumption for each type of individuals.

We assume that in the first period, when individuals make labour supply and saving decisions, the variables $R_{t+1}$ and $w_{t}$ are perfectly known to consumers. Conversely, as it will be clear in Section 2.3, the dependence of $p_{i, t+1}$ on the decision variable $l_{i, t}$ varies according to the existing pension system.

Concluding, given the own specific productivity level $h_{i}$, each individual chooses $s_{i, t}$, $l_{i, t}, c_{i, t}, c_{i, t+1}$ to maximize her life-cycle utility expressed by equation (1) under the

16 It is worth mentioning that Galor and Weil (1996) consider an OLG model with two types of workers with different abilities. Specifically they take into account male and female workers with the same abilities in mental labour but different ones in physical labour. 
constraints given by equations (2) and (3). The optimal solution to this optimization problem is:

$$
\begin{gathered}
s_{i, t}=\frac{\beta(1-\tau) w_{t} h_{i} l_{i, t}-\left(\beta l_{i, t}^{2} / 2\right)-\left(p_{i, t+1} / R_{t+1}\right)}{1+\beta}, \\
l_{i, t}=(1-\tau) w_{t} h_{i}+\frac{\partial p_{i, t+1} / \partial l_{i, t}}{R_{t+1}}
\end{gathered}
$$

Notice that both the decisions for savings $s_{i, t}$ and for labour supply $l_{i, t}$ depend on the pension system in force (i.e., through the terms $p_{i, t+1}$ and $\partial p_{i, t+1} / \partial l_{i, t}$, which will be discussed in detail in Section 2.3).

\subsection{Production}

Firms produce a single homogeneous good, according to a Cobb-Douglas technology exhibiting constant returns to scale. Therefore, the production function $F(K, L)$ is:

$$
F(K, L)=A K^{\alpha} L^{1-\alpha},
$$

where $K$ is the aggregate capital stock, $L$ is the aggregate labour input, and $\alpha \in(0,1)$.

Output and factor markets are competitive, which implies that at each time $t$, firms hire physical capital and labour until gross factor prices equal marginal products:

$$
\begin{gathered}
w_{t}=A(1-\alpha) k_{t}^{\alpha}, \\
R_{t}=\left(1+r_{t}\right)=A \alpha k_{t}^{\alpha-1},
\end{gathered}
$$

where $w_{t}$ is the wage rate at time $t$.

The labour market clearing condition yields:

$$
L_{t}=N_{t}\left(\lambda_{L} h_{L} l_{L, t}+\lambda_{H} h_{H} l_{H, t}\right) .
$$

We denote by $k_{t}=K_{t} / L_{t}$ the capital per efficiency unit at time $t$, which we can express as:

$$
k_{t}=\frac{K_{t}}{L_{t}}=\frac{K_{t}}{N_{t}\left(\lambda_{L} h_{L} l_{L, t}+\lambda_{H} h_{H} l_{H, t}\right)} .
$$

Finally, we define the capital per worker as:

$$
\frac{K_{t}}{N_{t}}=k_{t}\left(\lambda_{L} h_{L} l_{L, t}+\lambda_{H} h_{H} l_{H, t}\right) .
$$

\subsection{Pension systems and government budget constraint}

We compare, in terms of labour market distortions and physical capital accumulation, a PAYG NDC ${ }^{17}$ and a funded system that embodies an intragenerational component, i.e., the proposed MFF scheme.

17 A preliminary version of the PAYG NDC system described in this work appeared in the previous conference paper Wen et al. (2015). 


\subsubsection{PAYG NDC system}

In PAYG NDC, pensions are paid out of contributions of current workers. Therefore, since the State can directly tax the working population to finance the pensions of the retired generation, there is no need to accumulate assets in anticipation of future pension claims.

Consequently, the government budget constraint is balanced when the following equality holds:

$$
\begin{aligned}
\lambda_{L} p_{L, t+1}^{P A Y G N D C}+\lambda_{H} p_{H, t+1}^{P A Y G N C}= & \tau w_{t+1}^{P A Y G N D C}\left(\lambda_{L} h_{L} l_{L, t+1}^{P A Y G N D C}+\lambda_{H} h_{H} l_{H, t+1}^{P A Y G D C}\right) \\
& \times\left(1+\rho_{t+1}\right) .
\end{aligned}
$$

Regarding the link between contributions and benefits, the key characteristics of a PAYG NDC system are the payment of a pension whose present value depends entirely on the individual's contribution history, and the application of an interest rate set by government rules. As a result, the pension payments rule for low-skilled and high-skilled workers becomes:

$$
\frac{p_{L, t+1}^{P A Y G N C}}{p_{H, t+1}^{P A Y G N D C}}=\frac{h_{L} l_{L, t}^{P A Y G N D C}}{h_{H} l_{H, t}^{P A Y G N D C}} .
$$

Accordingly, combining equations (12) and (13), the pension benefits for a type $i$ agent under this pension system are expressed as follows:

$$
p_{i, t+1}^{P A Y G N C}=\tau w_{t}^{P A Y G N D C} h_{i} l_{i, t}^{P A Y G N D C}\left(1+\rho_{t+1}\right) \Omega_{t+1}^{P A Y G N D C},
$$

where $\Omega_{t+1}^{P A Y G N D C}$ denotes the growth factor of the economy's per capita income at time $t+1$, which is defined as:

$$
\Omega_{t+1}^{P A Y G N D C}=\frac{w_{t+1}^{P A Y G N D C}\left(\lambda_{L} h_{L} l_{L, t+1}^{P A Y G N C}+\lambda_{H} h_{H} l_{H, t+1}^{P A Y G N D C}\right)}{w_{t}^{P A Y G N D C}\left(\lambda_{L} h_{L} l_{L, t}^{P A Y G N D C}+\lambda_{H} h_{H} l_{H, t}^{P A Y G N D C}\right)} .
$$

\subsubsection{FF and MFF systems}

Differently from PAYG NDC, in FF, pensions are paid out of a fund built over a period of years from its members' contributions. Contributions are invested in financial or real assets, the return on which is credited to the fund. The main feature of this funded system is that it does not allow for redistribution across generations, since the position of each cohort is determined by its own past savings. Moreover, without any provision for within-cohort redistribution, at retirement each individual obtains no more than her first-period savings and her past contributions, together with the return yielded by the fund. Summing up, in a FF system, the government's budget is balanced when:

$$
\lambda_{L} p_{L, t+1}^{F F}+\lambda_{H} p_{H, t+1}^{F F}=R_{t+1}^{F F} \tau w_{t}^{F F}\left(\lambda_{L} h_{L} l_{L, t}^{F F}+\lambda_{H} h_{H} l_{H, t}^{F F}\right) .
$$


Moreover, the pension payments rule for the low-skilled and high-skilled workers is similar to (13), and is expressed as:

$$
\frac{p_{L, t+1}^{F F}}{p_{H, t+1}^{F F}}=\frac{h_{L} l_{L, t}^{F F}}{h_{H} l_{H, t}^{F F}} .
$$

Accordingly, by combining equations (16) and (17), the pension benefits for a type $i$ agent under this system are expressed as follows:

$$
p_{i, t+1}^{F F}=\tau w_{t}^{F F} h_{i} l_{i, t}^{F F} R_{t+1}^{F F} \text {. }
$$

The absence of redistribution across individuals, and thus the difficulties in pursuing poverty relief during retirement, give us room for proposing a modified version of the classical well-known FF system. The refinement of the original version that we introduce has the purpose to improve the living conditions for the low-skilled retirees, who may not save enough or accumulate enough in their fund for the retirement period.

Our MFF system works as the FF, but in addition disposes a withdrawal from every individuals' account before the beginning of the retirement period. The resources collected in this way are invested in a parallel fund that is used for redistribution once the same individuals become eligible for qualifying themselves as retirees.

Therefore, given $b \in[0,1]$, at the time of retirement every individual receives a pension which is made of two components:

$$
p_{i, t+1}^{M F F}=(1-b) p_{i, t+1}^{F F}+b p_{i, t+1}^{R} .
$$

The first part of the pension obtained in the MFF system, namely $(1-b) p_{i, t+1}^{F F}$, is the usual FF pension from which the withdrawal $b p_{i, t+1}^{F F}$ is taken away, while the second part corresponding to $b p_{i, t+1}^{R}$, where the superscript ' $R$ ' stands for redistribution, represents the additional benefit given to every individual irrespective of the skill/income level, i.e., the benefit needed to carry on intragenerational redistribution. Therefore, by definition, the redistributive component of $p_{i, t+1}^{M F F}$ obeys the rule: ${ }^{18}$

$$
p_{L, t+1}^{R}=p_{H, t+1}^{R},
$$

which simply expresses the fact that the resources in the aforementioned parallel fund are spread equally among the whole population irrespective of the income class and thus irrespective of the contributions one made when young.

Concluding, the two components of $p_{i, t+1}^{M F F}$ satisfy:

$$
p_{i, t+1}^{F F}=R_{t+1}^{M F F} \tau w_{t}^{M F F} h_{i} l_{i, t}^{M F F}
$$

and

$$
p_{i, t+1}^{R}=R_{t+1}^{M F F} \sum_{i=L, H} \lambda_{i} \tau w_{t}^{M F F} h_{i} l_{i, t}^{M F F}
$$

18 Notice that the other component of equation (19) satisfies equation (17). Clearly, when $b=0$ there is no withdrawal and the system becomes a pure FF. 


\section{General equilibrium}

The following definition introduces the general equilibrium within different social security systems.

Definition 1. Given the state of agents distribution in the economy and the productivity levels of low-skilled and high-skilled individuals, a general equilibrium is a sequence of individuals' decisions, a sequence of factor prices, and a sequence of pension payments so that:

(i) individuals choose $s_{i, t}, l_{i, t}, c_{i, t}, c_{i, t+1}$ to solve the maximization problem described by equations (1)-(3), taking the factor prices as given;

(ii) the factor markets clearing condition holds: the factor prices are equal to their marginal products, see equations (7) and (8);

(iii) the government budget constraint is satisfied, i.e., equations (14) and (15) are satisfied in the PAYG NDC system, while equations (19)-(22) are satisfied in the MFF system.

In particular, in an unfunded system the supply of capital in period $t+1$ is determined by the saving decision of the young in period $t$. Hence, the physical capital $K_{t+1}^{P A Y G N D C}$ in period $t+1$ is the sum of the aggregate previous period private savings:

$$
K_{t+1}^{P A Y G N D C}=\sum_{i=L, H} N_{t} \lambda_{i} s_{i, t}^{P A Y G N D C},
$$

where $s_{i, t}$ is provided by equation (4).

On the other hand, in a funded system, the aggregate physical capital consists both of private and public savings of the former period. Accordingly, the aggregate capital in the MFF case is:

$$
K_{t+1}^{M F F}=\sum_{i=L, H}\left(N_{t} \lambda_{i} s_{i, t}^{M F F}+N_{t} \lambda_{i} \tau w_{t}^{M F F} h_{i} l_{i, t}^{M F F}\right) .
$$

\subsection{General equilibrium in the PAYG NDC system}

We find the general equilibrium for the PAYG NDC system and summarize the result in Proposition 1 (details of derivation are provided in the Appendix). In part (i), we provide the labour supply choice $l_{i, t}^{P A Y G N D C}$ of both high- and low-skilled workers, which holds at any time $t$. In part (ii), we express, for each time $t$, the just-mentioned optimal labour supply as a function of the capital per efficiency unit $k_{t}^{P A Y G N D C}$. In part (iii), we provide a recursive way to compute $k_{t+1}^{P A Y G N D C}$ knowing $k_{t}^{P A Y G N D C}$. Finally, in part (iv), we show that, when the population growth rate is constant and equal to $1+\rho$, one obtains a unique non-trivial steady-state solution (one characterized by non-zero values of individual labour supply choices, of capital per efficiency unit, of capital per worker and of pensions). Moreover, for both high- and low-skilled workers, we provide the general expression of the PAYG NDC pension and its nontrivial steady-state value $p_{i}^{P A Y G N D C}$. In particular, for $\alpha \in(0,(1 / 3))$, the pension decreases as the population growth rate reduces (all the other parameters being 
fixed). This is a case of interest, since the values of $\alpha$ in this range are often encountered in the literature (see Bouzahzah et al. (2002)).

Proposition 1 [PAYG NDC]. The following holds for the general equilibrium of the PAYG NDC system with the specification (1) of the utility function.

(i) Relationship between individual labour supply choice and capital per efficiency unit:

$$
\begin{aligned}
l_{i, t}^{P A Y G N D C}= & \frac{[\beta \tau(1-\alpha)+2 \alpha(1+\beta)+\tau(1-\alpha)(2+\beta)](1-\alpha)(1-\tau) A h_{i}}{2 \alpha(1+\beta)+\tau(1-\alpha)(2+\beta)} \\
& \left(k_{t}^{P A Y G N D C}\right)^{\alpha} .
\end{aligned}
$$

(ii) Relationship between labour supply choices of high- and low-skilled individuals:

$$
l_{H, t}^{P A Y G N C}=\frac{h_{H}}{h_{L}} l_{L, t}^{P A Y N D C} .
$$

(iii) Recursive formula for the capital per efficiency unit:

$$
k_{t+1}^{P A Y G N D C}=\left[\frac{A \alpha \beta(1-\alpha)(1-\tau)}{[2 \alpha(1+\beta)+\tau(1-\alpha)(2+\beta)]\left(1+\rho_{t+1}\right)}\right]^{1 / 1+\alpha}\left(k_{t}^{P A Y G N D C}\right)^{2 \alpha / 1+\alpha} .
$$

(iv) Unique non-trivial steady-state solution $\left(\rho_{t}=\rho\right.$ for all $\left.t\right)$ :

$$
\begin{aligned}
& k^{P A Y G N D C}=\left[\frac{A \alpha \beta(1-\alpha)(1-\tau)}{[2 \alpha(1+\beta)+\tau(1-\alpha)(2+\beta)](1+\rho)}\right]^{1 / 1-\alpha}, \\
& \frac{K_{t}^{P A Y G N D C}}{N_{t}}=\left(\lambda_{L} h_{L}^{2}+\lambda_{H} h_{H}^{2}\right)(1-\tau) A(1-\alpha) \\
& \times \frac{\beta \tau(1-\alpha)+2 \alpha(1+\beta)+\tau(1-\alpha)(2+\beta)}{2 \alpha(1+\beta)+\tau(1-\alpha)(2+\beta)} \\
& \times\left[\frac{A \alpha \beta(1-\alpha)(1-\tau)}{[2 \alpha(1+\beta)+\tau(1-\alpha)(2+\beta)](1+\rho)}\right]^{1+\alpha / 1-\alpha}, \\
& l_{i}^{P A Y G N D C}=(1-\tau) A(1-\alpha) \frac{\beta \tau(1-\alpha)+2 \alpha(1+\beta)+\tau(1-\alpha)(2+\beta)}{2 \alpha(1+\beta)+\tau(1-\alpha)(2+\beta)} \\
& \times\left[\frac{A \alpha \beta(1-\alpha)(1-\tau)}{[2 \alpha(1+\beta)+\tau(1-\alpha)(2+\beta)](1+\rho)}\right]^{\alpha / 1-\alpha} h_{i}, \\
& p_{i}^{P A Y G N D C}=\tau(1-\tau) A^{2}(1-\alpha)^{2} \frac{\beta \tau(1-\alpha)+2 \alpha(1+\beta)+\tau(1-\alpha)(2+\beta)}{2 \alpha(1+\beta)+\tau(1-\alpha)(2+\beta)} \\
& \times\left[\frac{A \alpha \beta(1-\alpha)(1-\tau)}{[2 \alpha(1+\beta)+\tau(1-\alpha)(2+\beta)]}\right]^{2 \alpha / 1-\alpha} h_{i}^{2}(1+\rho)^{1-3 \alpha / 1-\alpha} .
\end{aligned}
$$

It is worth noting that according to equation (26), the labour supply choice of the high-skilled is always larger than the one of the low-skilled. Moreover, from Proposition 1, one can derive closed-form expressions also for other quantities of 
interest, such as the optimal consumption for each type of worker $\left(c_{i, \text { young }}^{P A Y G C}\right.$ and $c_{i, \text { old }}^{P A Y G N D C}$ in the first and second periods, respectively, not reported here due to space limitations), and the associated utility, which is defined as

$$
U_{i}^{\text {PAYG NDC }}=\ln \left(c_{i, \text { young }}^{\text {PAYG NDC }}-\frac{\left(l_{i}^{\text {PAYG NDC }}\right)^{2}}{2}\right)+\beta \ln c_{i, \text { old }}^{\text {PAYG NDC }},
$$

its average over the population

$$
U^{P A Y G N D C}=\lambda_{L} U_{L}^{P A Y G N D C}+\lambda_{H} U_{H}^{P A Y G N D C},
$$

and the (average) pension per worker, represented by

$$
p^{P A Y G N D C}=\lambda_{L} p_{L}^{P A Y G N D C}+\lambda_{H} p_{H}^{P A Y G N D C} .
$$

Closed-form expressions for the partial derivatives of equations (28)-(34) with respect to the parameters are obtained by automatic differentiation. Since the resulting expressions are quite lengthy, ${ }^{19}$ we perform a numerical investigation to analyse how the results are affected by changes in the values of the parameters (see Section 4). Additionally, in the Appendix we report the signs of the partial derivatives of several quantities of interest at the non-trivial PAYG NDC steady state.

\subsection{General equilibrium in the MFF system}

Proposition 2 summarizes the general equilibrium in a MFF system (details of derivation are provided in the Appendix). For this proposition, one can make comments similar to those stated before Proposition 1. Additionally, in part (iv), we provide, for both high- and low-skilled workers, the steady-state expression of the MFF pension divided in its two components: $(1-b) p_{i}^{F F}$ and $b p_{i}^{R}$. In particular for $\alpha \in(0,(1 / 3))$, both components decrease as the population growth rate reduces (all the other parameters being fixed).

Proposition 2 [MFF]. The following holds for the general equilibrium of the MFF system with the specification (1) of the utility function.

(i) Relationship between individual labour supply choice and capital per efficiency unit:

$$
l_{i, t}^{M F F}=\left(1-b \tau\left(1-\lambda_{i}\right)\right) A(1-\alpha) h_{i}\left(k_{t}^{M F F}\right)^{\alpha} .
$$

(ii) Relationship between labour supply choices of high- and low-skilled individuals:

$$
l_{H, t}^{M F F}=\frac{\left(1-b \tau \lambda_{L}\right) h_{H}}{\left(1-b \tau \lambda_{H}\right) h_{L}} l_{L, t}^{M F F} .
$$

19 See the Appendix of Wen et al. (2015) for some of these expressions. 
(iii) Recursive formula for the capital per efficiency unit:

$$
k_{t+1}^{M F F}=\left[\frac{A \beta\left[\lambda_{L} h_{L}^{2}+\lambda_{H} h_{H}^{2}-b^{2} \tau^{2}\left(\lambda_{H} h_{L}^{2}+\lambda_{L} h_{H}^{2}\right) \lambda_{L} \lambda_{H}\right](1-\alpha)}{2(1+\beta)\left(1+\rho_{t+1}\right)\left[\lambda_{L} h_{L}^{2}+\lambda_{H} h_{H}^{2}-b \tau\left(h_{L}^{2}+h_{H}^{2}\right) \lambda_{L} \lambda_{H}\right]}\right]^{1 / 1+\alpha}\left(k_{t}^{M F F}\right)^{2 \alpha / 1+\alpha} .
$$

(iv) Unique non-trivial steady-state solution $\left(\rho_{t}=\rho\right.$ for all $\left.t\right)$ :

$$
\begin{aligned}
& k^{M F F}=\left[\frac{A \beta\left[\lambda_{L} h_{L}^{2}+\lambda_{H} h_{H}^{2}-b^{2} \tau^{2}\left(\lambda_{H} h_{L}^{2}+\lambda_{L} h_{H}^{2}\right) \lambda_{L} \lambda_{H}\right](1-\alpha)}{2(1+\beta)(1+\rho)\left[\lambda_{L} h_{L}^{2}+\lambda_{H} h_{H}^{2}-b \tau\left(h_{L}^{2}+h_{H}^{2}\right) \lambda_{L} \lambda_{H}\right]}\right]^{1 / 1-\alpha}, \\
& \frac{K_{t}^{M F F}}{N_{t}}=\left[\lambda_{L} h_{L}^{2}+\lambda_{H} h_{H}^{2}-b \tau \lambda_{L} \lambda_{H}\left(h_{L}^{2}+h_{H}^{2}\right)\right] \\
& \times A(1-\alpha)\left[\frac{A \beta\left[\lambda_{L} h_{L}^{2}+\lambda_{H} h_{H}^{2}-b^{2} \tau^{2}\left(\lambda_{H} h_{L}^{2}+\lambda_{L} h_{H}^{2}\right) \lambda_{L} \lambda_{H}\right](1-\alpha)}{2(1+\beta)(1+\rho)\left[\lambda_{L} h_{L}^{2}+\lambda_{H} h_{H}^{2}-b \tau\left(h_{L}^{2}+h_{H}^{2}\right) \lambda_{L} \lambda_{H}\right]}\right]^{1+\alpha / 1-\alpha}, \\
& l_{i}^{M F F}=\left(1-b \tau\left(1-\lambda_{i}\right)\right) A(1-\alpha) \\
& \times\left[\frac{A \beta\left[\lambda_{L} h_{L}^{2}+\lambda_{H} h_{H}^{2}-b^{2} \tau^{2}\left(\lambda_{H} h_{L}^{2}+\lambda_{L} h_{H}^{2}\right) \lambda_{L} \lambda_{H}\right](1-\alpha)}{2(1+\beta)(1+\rho)\left[\lambda_{L} h_{L}^{2}+\lambda_{H} h_{H}^{2}-b \tau\left(h_{L}^{2}+h_{H}^{2}\right) \lambda_{L} \lambda_{H}\right]}\right]^{\alpha / 1-\alpha} h_{i}, \\
& (1-b) p_{i}^{F F}=\tau\left(1-b \tau\left(1-\lambda_{i}\right)\right)(1-b) A^{3}(1-\alpha)^{2} \alpha \\
& \times\left[\frac{A \beta\left[\lambda_{L} h_{L}^{2}+\lambda_{H} h_{H}^{2}-b^{2} \tau^{2}\left(\lambda_{H} h_{L}^{2}+\lambda_{L} h_{H}^{2}\right) \lambda_{L} \lambda_{H}\right](1-\alpha)}{2(1+\beta)\left[\lambda_{L} h_{L}^{2}+\lambda_{H} h_{H}^{2}-b \tau\left(h_{L}^{2}+h_{H}^{2}\right) \lambda_{L} \lambda_{H}\right]}\right]^{3 \alpha-1 / 1-\alpha} \\
& \times h_{i}^{2}(1+\rho)^{1-3 \alpha / 1-\alpha} \text {, } \\
& b p_{i}^{R}=\tau A^{3} b(1-\alpha)^{2} \alpha\left[\frac{A \beta\left[\lambda_{L} h_{L}^{2}+\lambda_{H} h_{H}^{2}-b^{2} \tau^{2}\left(\lambda_{H} h_{L}^{2}+\lambda_{L} h_{H}^{2}\right) \lambda_{L} \lambda_{H}\right](1-\alpha)}{2(1+\beta)\left[\lambda_{L} h_{L}^{2}+\lambda_{H} h_{H}^{2}-b \tau\left(h_{L}^{2}+h_{H}^{2}\right) \lambda_{L} \lambda_{H}\right]}\right]^{3 \alpha-1 / 1-\alpha} \\
& \times\left[\lambda_{L}\left(1-b \tau\left(1-\lambda_{L}\right)\right) h_{L}^{2}+\lambda_{H}\left(1-b \tau\left(1-\lambda_{H}\right)\right) h_{H}^{2}\right](1+\rho)^{1-3 \alpha / 1-\alpha} .
\end{aligned}
$$

According to equation (36), for $\lambda_{L}=\lambda_{H}=1 / 2$, the labour supply choice of the highskilled is always larger than the one of the low-skilled. The same occurs for $\lambda_{L} \neq \lambda_{H}$ and for $b=0$. The opposite occurs when $\lambda_{L}>\lambda_{H}$ and $b$ is sufficiently large. Additionally, likewise in Section 3.1, from Proposition 2 one can derive closed-form expressions for the optimal consumption for each type of worker $\left(c_{i, \text { young }}^{\text {MFF }}\right.$ and $c_{i, \text { old }}^{\text {MFF }}$ in the first and second periods, respectively, not reported here due to space limitations), and the associated utility, which is defined as

$$
U_{i}^{M F F}=\ln \left(c_{i, \text { young }}^{M F F}-\frac{\left(l_{i}^{M F F}\right)^{2}}{2}\right)+\beta \ln c_{i, \text { old }}^{M F F},
$$

its average over the population

$$
U^{M F F}=\lambda_{L} U_{L}^{M F F}+\lambda_{H} U_{H}^{M F F}
$$


the pension for each type of the worker, which is

$$
p_{i}^{M F F}=(1-b) p_{i}^{F F}+b p_{i}^{R},
$$

and the (average) pension per worker, which has the expression

$$
p^{M F F}=\lambda_{L} p_{L}^{M F F}+\lambda_{H} p_{H}^{M F F} .
$$

Again, closed-form expressions for the partial derivatives of equations (38)-(46) with respect to the parameters are obtained by automatic differentiation but are not reported here due to space limitations. In the Appendix, we report the signs of the partial derivatives of several quantities of interest at the non-trivial MFF (and FF) steady state.

\subsection{Main findings}

As we have just seen, equation (30) displays the agents' steady-state labour supply under the unfunded NDC system. By assuming a dynamically efficient economy, where the return on PAYG NDC is lower than the market interest rate, high- and low-skilled workers tend to reduce the amount of labour supplied since they realize the missed opportunity of investing their contributions in stocks, bonds, or anything else. Conversely, equation (40) shows the agents' steady-state labour supply under the MFF system. If we take a step back, and thus if we set the individual fund's withdrawal to be equal to zero (i.e., $b=0$ ), we get the original version of the funded system. In a pure FF scheme, a variation in the contribution rate has no effect on individual labour supply, irrespective of whether the worker is high- or low-skilled. This is a clear-cut result since, in a pure FF, individuals are aware that the payment of contributions into their own account is simply another form of private savings. Conversely, the introduction of a redistributive component in the funded pension $(b>0)$ creates labour supply distortions for both high- and low-skilled workers. In a MFF system, in fact, the former know that they will 'lose', while the latter know that they will 'gain' with respect to the pure FF. By looking at equation (35), we can see that the larger are the withdrawal $b$, the contribution rate $\tau$, and the percentage of high-skilled individuals in the population, the smaller is the incentive to work of low-skilled agents. ${ }^{20}$ Conversely, when the economy is mainly composed of lowskilled individuals, high levels of both $b$ and $\tau$ will create a disincentive to work for the high-skilled.

Regarding the capital accumulation, which is expressed by equations (28) and (38), we find that in both PAYG NDC and pure FF $(b=0)$, the level of capital per efficiency unit does not depend on the sizes of more productive/less-productive groups. Conversely, as it will be clearer in the next section, in a MFF system with $b \neq 0$, the composition of the population matters since individuals adjust their choices over consumption and saving according to the utility they receive from redistribution.

20 The higher is the withdrawal from each individual's account, the higher is the weight of the redistribution. For $b=1$, we have a system where individuals receive the same benefit no matter of their productivity type. 
Finally, both Propositions 1 and 2 support that the individual's labour supply at the steady state is higher in an ageing economy (i.e., when $-1<\rho_{t+1}<0$ ) with respect to the case in which the population is increasing from time $t$ to time $t+1$ (i.e., when $\left.\rho_{t+1}>0\right)$.

A deeper analysis of the changes in the individuals' labour supply and saving decision under both PAYG NDC and MFF is provided in Section 4, where we complement the steady-state analysis with a numerical investigation for realistic values of the parameters.

\section{Numerical results}

The following subsections, namely Sections 4.1-4.3, show for the different pension systems and for both high- and low-skilled workers, the non-trivial steady-state values of labour supply choice, capital accumulation, pension, and utility, expressed as functions of the parameter $\tau$, for fixed values of the other parameters $\alpha, \beta, A, h_{L}, h_{H}, \lambda_{L}$, and $\rho$. Therefore, the equations we have to focus on are equations (25)-(46). In particular, we choose the values $\alpha=0.29$ and $A=8$ following Bouzahzah et al. (2002). Moreover, we set $\beta=0.96, h_{L}=0.5, h_{H}=1, \lambda_{L}=0.3, \lambda_{L}=0.7$, and $\rho=0 .{ }^{21}$ Additionally, in the Appendix, we investigate how the individual labour supply decision reacts to changes in $\rho$ when the contribution rate is equal to 0.1 and 0.4 , provided the other variables are set at the aforementioned values.

\subsection{Labour supply}

In a dynamically efficient economy with a PAYG NDC system, irrespective of the proportion of high- and low-skilled workers, an increase of the contribution rate $\tau$ will always decrease the labour supply of both high- and low-skilled workers (see Figure 1). Since the contributions paid by individuals during the entire working career are used to finance pensions of current period retirees, each worker's claim for a pension is only based on the promise that future generations will be responsible for providing the benefit. Therefore, since the worker sees that the contributions she is paying now are revaluated at a lower interest rate than the market return, she will be more willing to supply less amount of labour.

In a pure FF system $(b=0)$, irrespective of the proportion of high- and low-skilled workers in the economy, the labour supply of high- and low-skilled workers is not related to the level of the contribution rate $\tau$. The worker is fully aware that the contribution that she is paying during the working career is accumulated in a personal account to which she will have access at the time of retirement.

In order to illustrate the MFF system, we chose for simplicity a redistribution component $b$ equal to 0.3 . From the plots in Figure 1, it is easy to see that when the proportion of high-skilled individuals prevails, i.e., when $\lambda_{L}=0.3$, while the labour supply distortion for high-skilled workers is the smallest, the labour supply distortion for low-skilled workers is the highest. When the composition of the population is the

${ }^{21}$ We use $\lambda_{L}=0.3$ to describe an economy mainly composed of high-skilled workers. Conversely, we use $\lambda_{L}=0.7$ to represent an economy where the majority of people belongs to the low-skilled class. 

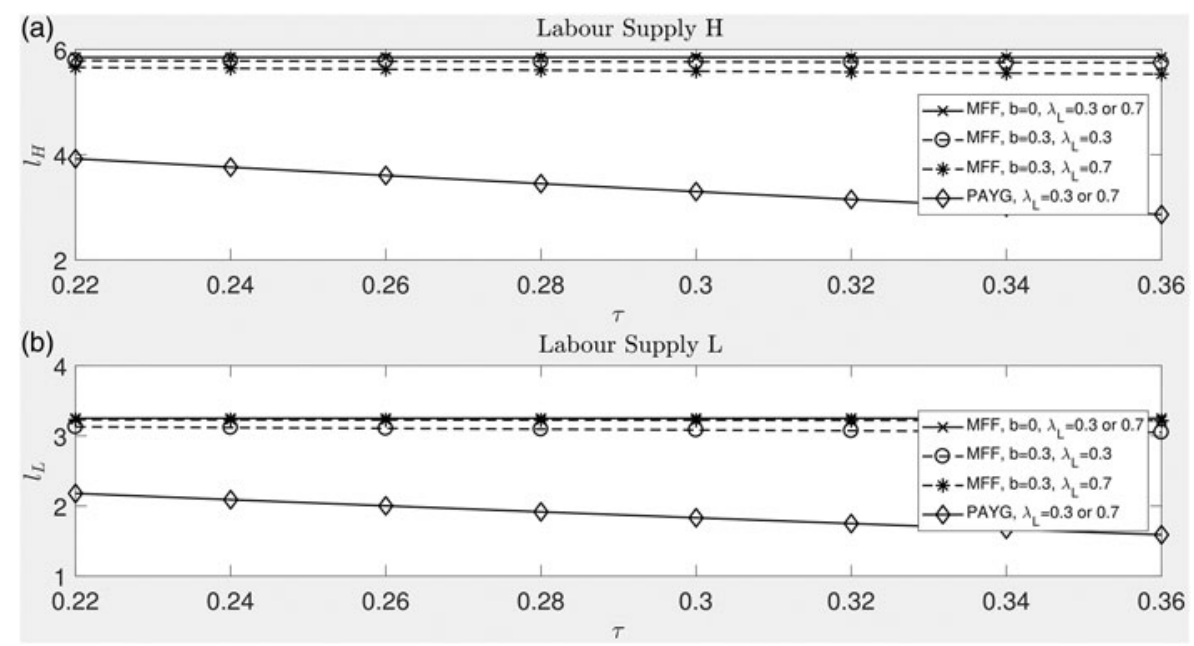

Figure 1. Labour supply of high- and low-skilled workers. Source: Authors' calculations.

one just mentioned, high-skilled individuals realize that the amount that they receive back with redistribution will be not much different from the fraction $b$ that was previously taken from each individual account. For the same reason, low-skilled workers are more inclined to work less since they know, due to the presence of a majority of high-skilled individuals in the economy, that they will attain a higher than expected pension from redistribution.

\subsection{Capital accumulation}

In order to understand the behaviour of the steady-state capital per worker $K_{t} / N_{t}$, which is illustrated in Figure 2, we first present separately in Figures 3(a) and (b) the capital per high-skilled and low-skilled individuals.

By looking at Figures 3(a) and (b), we see that in a PAYG NDC system, when the contribution rate increases, both the capital per high-skilled and low-skilled worker tend to decrease, irrespective of the proportion of high- and low-skilled workers in the economy. This depends on the fact that, for such system, it can be shown that, when the contribution rate increases, the disposable income in the first period decreases and so do the savings (see the Appendix). Obviously, for a given level of $\tau$, the level of capital per worker for the high-skilled is higher than the one for the low-skilled.

Similarly, in a pure FF, for both high- and low-skilled workers, as $\tau$ increases the disposable income in the first period decreases and so do the savings. However, when the contribution rate increases, the resources accumulated in each worker's individual account rise. Overall, since the worker's future pension is generated by her personal first-period savings and paid contribution, the capital per high- and low-skilled worker is independent on the level of $\tau$. Needless to say that, for a specific level of the tax rate, the capital per worker for the high-skilled is higher than the one for the low-skilled. 


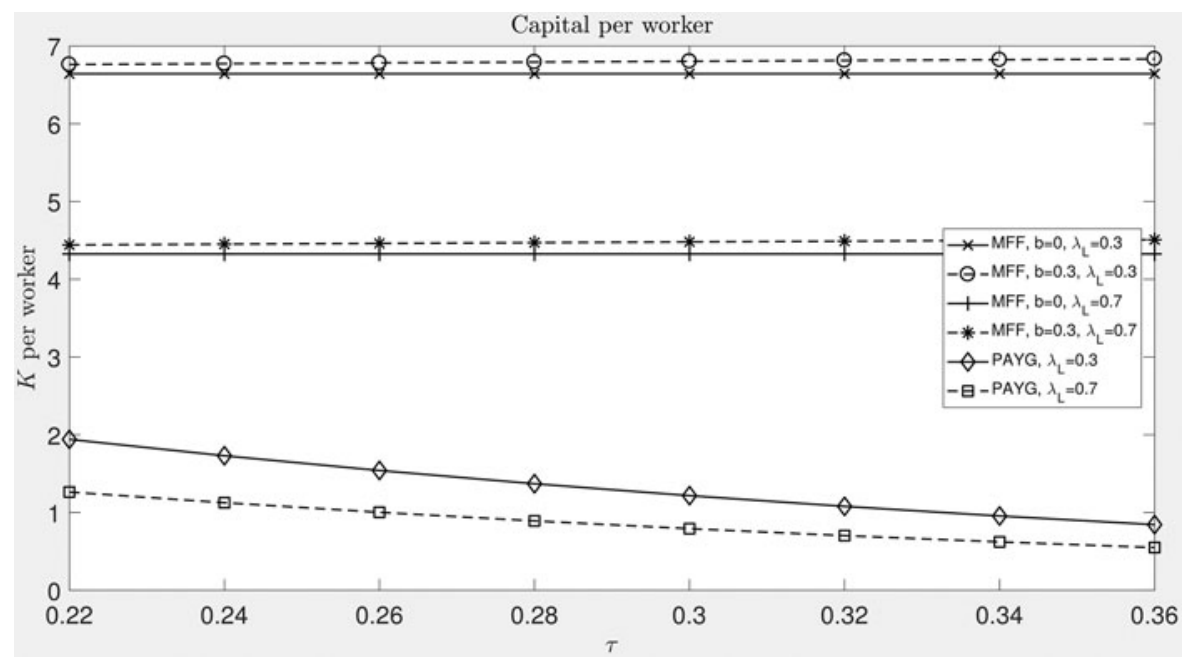

Figure 2. Capital per worker. Source: Authors' calculations.

In MFF, the analysis becomes more complex. In order to make the discussion as clear as possible, we present the behaviour of the high-skilled followed by the one of the low-skilled, i.e., we discuss Figure 3(a) and then Figure 3(b).

For the high-skilled workers, it can be shown from the formulas used to prove Proposition 2 (see the Appendix) that:

1. first-period savings are higher than in the case of pure FF $(b=0)$;

2. first-period savings are the highest when the proportion of low-skilled individual prevails, i.e., when $\lambda_{L}=0.7$;

3 . the amount of resources invested in the individual account is lower than in the pure FF $(b=0)$;

4. the amount of resources invested in the individual account is the lowest when the proportion of low-skilled individual prevails, i.e., when $\lambda_{L}=0.7$.

Since high-skilled workers know that a fraction $b$ of their individual account will be withdrawn for redistribution purposes, as $\tau$ increases, they will be more prone to increase their personal savings in the first period, and to accumulate a lower amount of capital on their personal fund..$^{22}$ Actually, by expanding the savings in the first period and by reducing the accumulation of resources in their account, high-skilled individuals preserve themselves from the large withdrawal associated to a richer fund. In a world where low-skilled individuals are the majority, if high-skilled individuals do not modify their choices on consumption and savings accordingly, as $\tau$ increases the amount that they get back once redistribution has occurred will be much lower than what they gave in first place.

As can be seen from Figure 3(a), as $\tau$ increases, in the MFF, the choices of highskilled workers are distorted with respect to the pure FF case: they save more and

22 More precisely, the reduction of both periods consumption experienced in MFF by high-skilled workers is higher than in a pure FF case, and is the highest when the proportion of low-skilled individual prevails, i.e., when $\lambda_{L}=0.7$. 

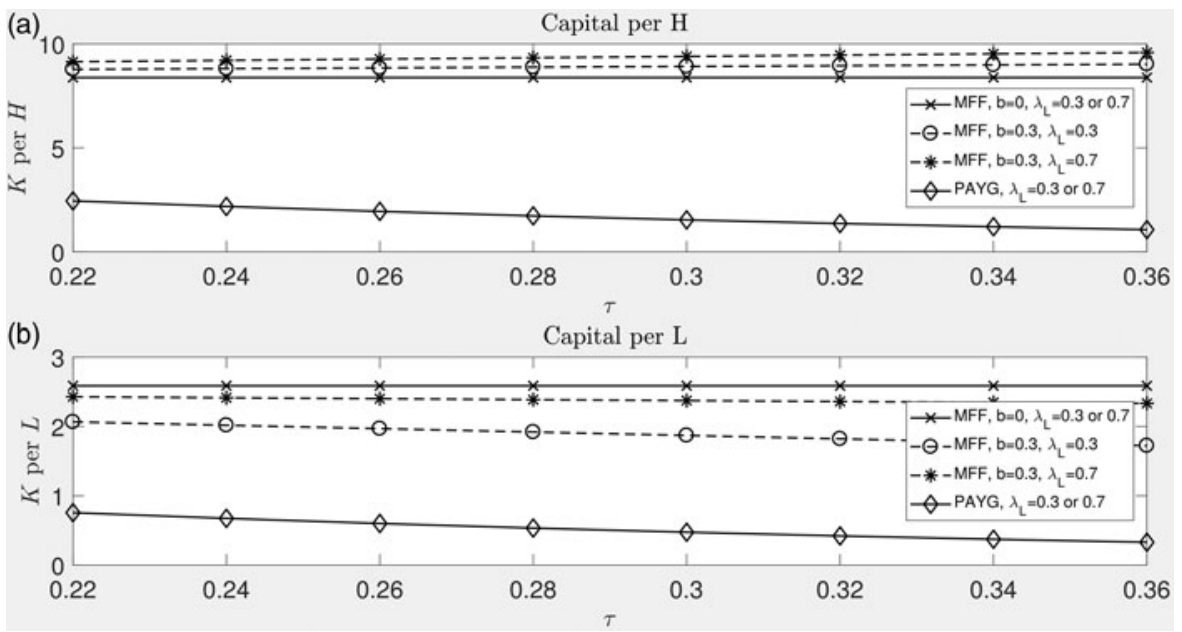

Figure 3. Capital per high- and low-skilled workers. Source: Authors' calculations.

consume less. More precisely, the overall effect on the capital accumulation per highskilled worker is positive with respect to the original FF system.

Conversely, for low-skilled workers it can be shown that:

1. first-period savings are lower than in the case of pure FF (when $b=0$ );

2. first-period savings are the lowest when the proportion of high-skilled individual prevails, i.e., when $\lambda_{L}=0.3$;

3 . the amount of resources invested in the individual account is the lowest when the proportion of high-skilled individuals prevails, i.e., when $\lambda_{L}=0.3$.

One can easily see that, since low-skilled individuals know that there will be a redistribution, as $\tau$ increases, they will distort their choices over savings and consumption in both periods. ${ }^{23}$ With respect to the pure FF case, as $\tau$ increases, if the high-skilled group is the largest one, in addition to a reduction in the first-period savings, lowskilled workers tend to reduce the capital accumulation in their account. Conversely, when high-skilled workers are the minority and $\tau$ rises, in addition to the decrease of first-period savings, low-skilled workers are likely to increase the resources accumulated in the personal fund (they know that the gains obtained from the redistribution are not so high).

Therefore, from Figure 3(b) we see that, as $\tau$ increases, the choices of low-skilled workers diverge from the pure FF case: they save less and consume more. In particular, in a MFF scheme, the overall effect on the capital accumulation per low-skilled worker is negative, as compared with the original FF.

We can now move to the interpretation of Figure 2. From the analysis conducted above, we have seen that while in a PAYG NDC a rise in the contribution rate $\tau$ depresses the level of capital per worker, in a pure FF system, the same variation

23 It can be shown that in an MFF there is an increase of both periods consumption experienced by lowskilled workers. Such increase is higher than in a pure FF, and is the highest when the proportion of highskilled individual prevails, i.e., when $\lambda_{L}=0.3$. 


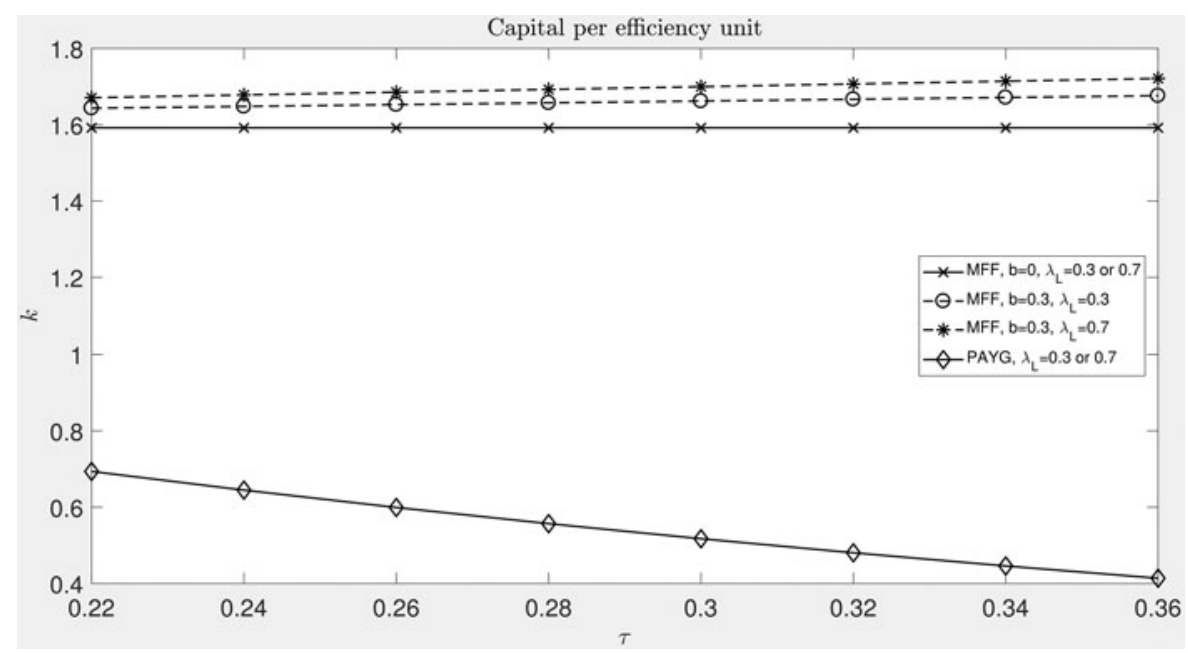

Figure 4. Capital per efficiency unit. Source: Authors' calculations.

in $\tau$ has no effect on capital accumulation. Conversely, in a MFF, as $\tau$ increases, the rise in savings experienced by high-skilled workers prevails on the reduction of the same driven by the behaviour of low-skilled individuals. Consequently, the introduction of a redistributive component in a pure funded system induces an increase in the accumulation of capital per worker.

As regards the behaviour of capital per efficiency unit under PAYG NDC, FF, and MFF, we find the result reported in Figure 4, from which we can infer that the capital per efficiency unit is the highest when the pension system is a MFF, and when the population is largely composed by low-skilled workers.

By recalling equation (11) and the results presented in Figure 1 above, we conclude that in the MFF scheme, provided the existence of a reduction in the labour supply by both groups of individuals (high- and low-skilled workers), labour supply contraction is higher when the proportion of low-skilled individuals prevails. More precisely, the negative impact that a redistributive component has on the labour offer of high-skilled workers is as much higher as the fraction of low-skilled workers in the economy. Obviously, it follows that the lower is the amount of labour supplied, the higher is $k$.

\subsection{Pension and utility per worker}

In this subsection, we provide for each type of worker, the steady-state value of the pension under different pension schemes. In particular, Figure 5 illustrates the pension as a function of $\tau$ with all other parameters being fixed at the values reported at the beginning of this section. Furthermore, Figure 6 represents the (average) pension per worker in different systems.

From Figure 5, one can see that in both FF and MFF systems, the pension for each type of worker is much higher than in the PAYG NDC scheme. As expected, for the low-skilled workers, the pension increases when moving from the FF to the MFF system (the increase is larger when the low-skilled are the minority). Conversely, for the 

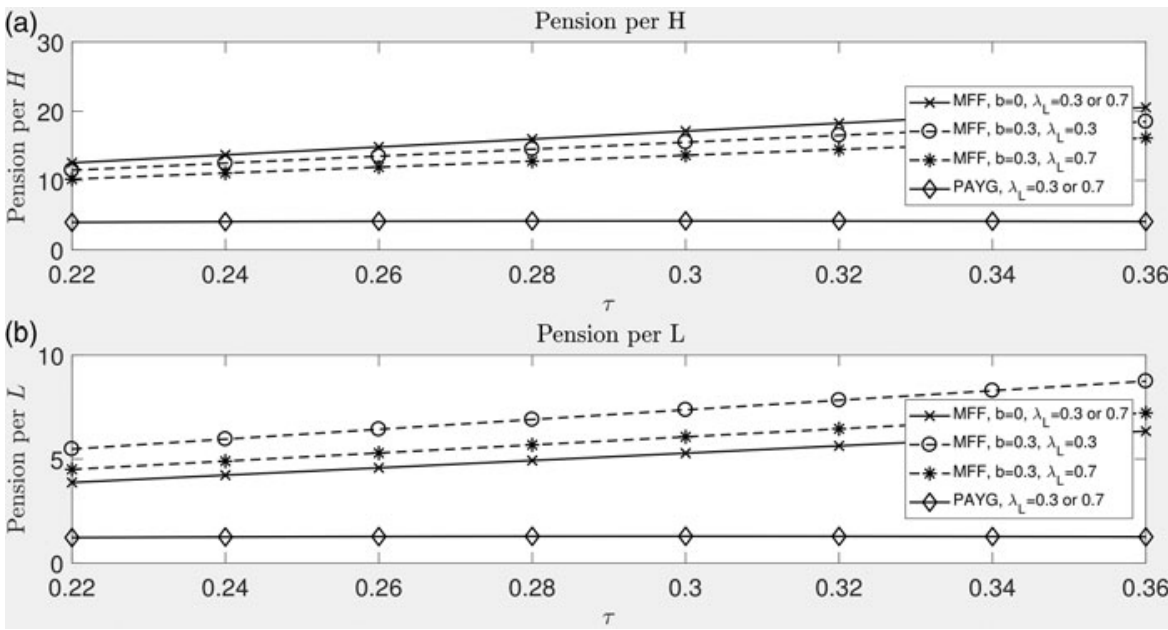

Figure 5. Pension per high- and low-skilled workers. Source: Authors' calculations.

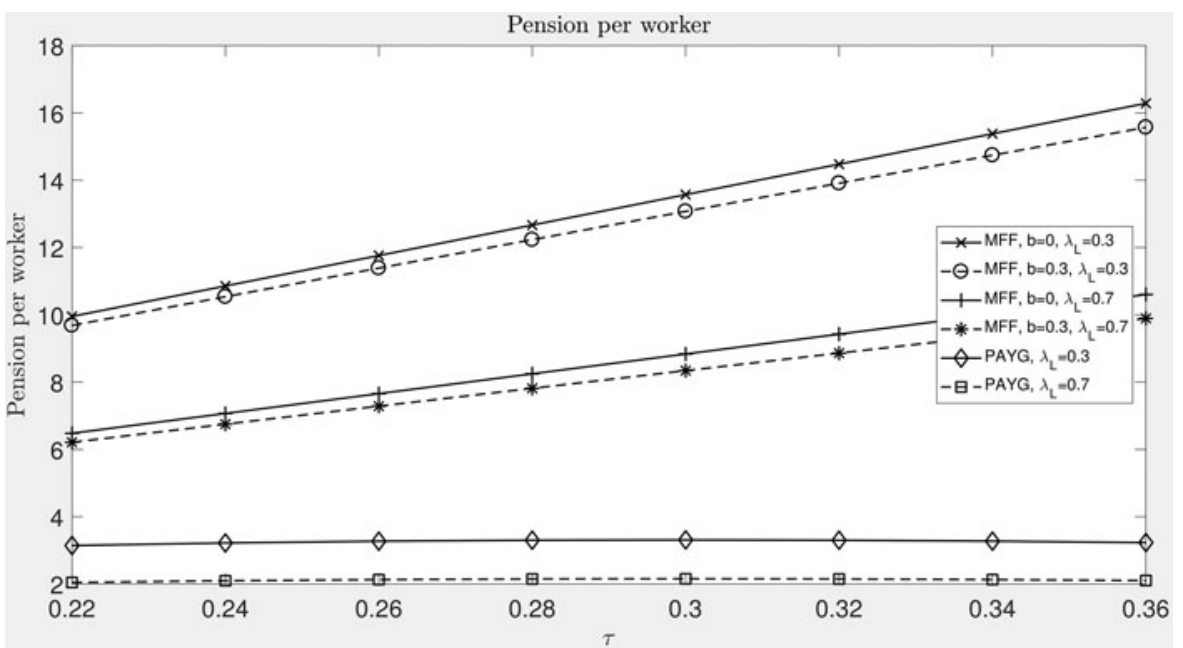

Figure 6. Pension per worker. Source: Authors' calculations.

high-skilled workers, the pension decreases when shifting from the FF to the MFF scheme (the decrease is smaller when the high-skilled are the majority).

Similarly, Figure 6 shows that the pension per worker is higher in the FF and MFF systems than in the PAYG NDC. The figure also shows that the average pension increases when increasing the percentage of the high-skilled in the economy. Moreover, the average pension (slightly) decreases when moving from the FF to the MFF system. Nevertheless, this is compensated by its beneficial effect on the pension per low-skilled and on the average utility per worker, which is examined in the following paragraphs.

Figures 7 and 8 illustrate, respectively, the utility for each type of worker and the (average) utility per worker. They refer to equations (32) and (33) for the PAYG 

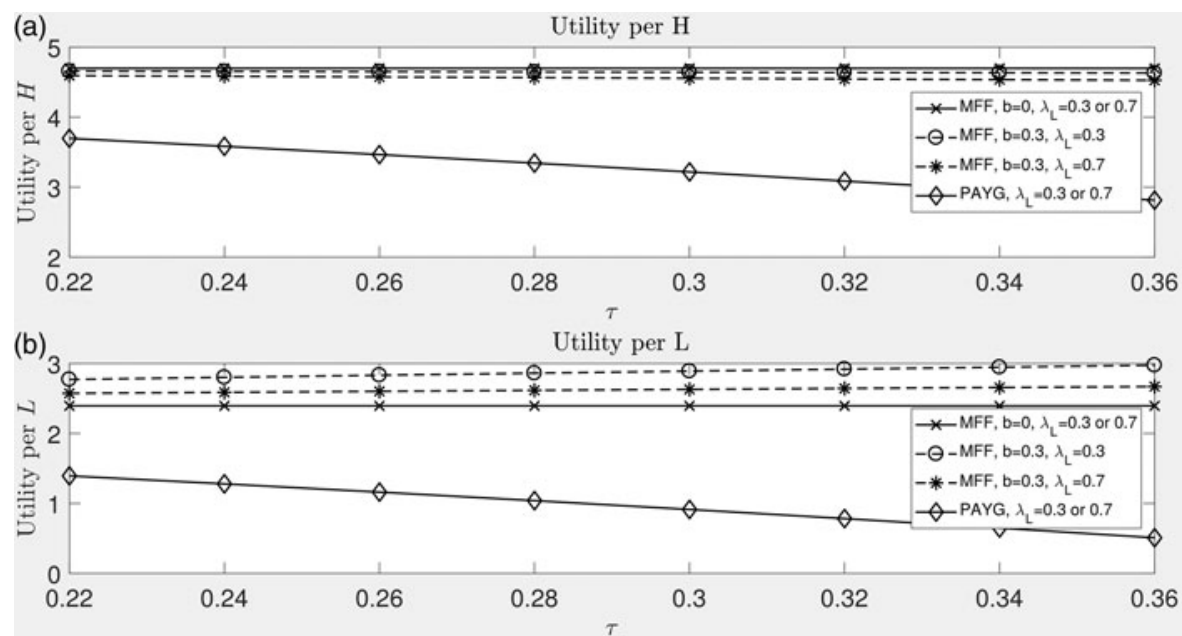

Figure 7. Utility per high- and low-skilled workers. Source: Authors' calculations.

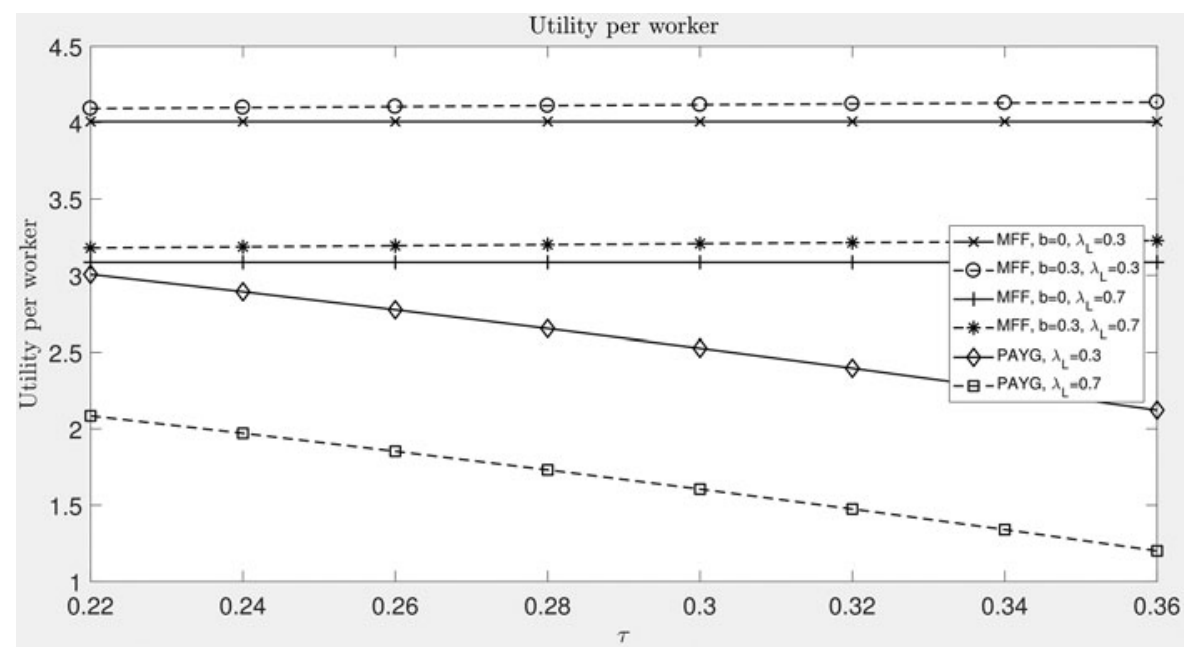

Figure 8. Utility per worker. Source: Authors' calculations.

NDC, and to equations (43) and (44) for the MFF. Similarly to Figure 5, Figure 7 shows that in both FF and MFF systems, the utility for each type of worker is much higher than in the PAYG NDC. For low-skilled workers, the utility increases when moving from the FF to the MFF system (the lower the share of the low-skilled, the larger the increase). Differently, for high-skilled workers, the utility decreases when moving from the FF to the MFF system (the larger the share of the high-skilled, the smaller the decrease). Interestingly, in the range of parameter values examined, the reduction of utility of the high-skilled is much smaller than the increase of utility of the low-skilled. As a result, as shown in Figure 8, the utility per worker increases when moving from the pure FF to the MFF system. In contrast, the PAYG NDC is characterized by much smaller values of the utility per worker. 
Hence, if one adopts the utility per worker as a social welfare function, ${ }^{24}$ from a social welfare perspective, in the range of parameter values examined, the MFF pension system is preferable to both the FF and the PAYG NDC schemes.

\section{Conclusion}

Ageing population and declining fertility rates require reforms that could help in creating more financially sustainable pension systems. The most credited solution, which consists in the privatization of social security, defined as the shift from unfunded PAYG schemes to funded systems, does not come without disadvantages. In fact, while it allows overcoming the solvency problems of unfunded schemes, it is not designed to address poverty relief and redistribution.

In a general equilibrium framework, this paper studies the properties, in terms of labour market distortions and capital accumulation, of different social security systems. Keeping in mind the solvency problems induced by declining fertility and rising longevity, we focus on three pension systems: the unfunded PAYG NDC, the FF, and the MFF system, which is a modified version of the FF system incorporating an intra cohort redistributive component. According to our results, while the PAYG NDC scheme depresses labour supply and physical capital accumulation, the FF system discourages neither of the two. Furthermore, in the newly proposed MFF, where the redistributive component takes the form of a withdrawal from each individual's account, while highskilled workers consume less and increase their private savings in order to own a scarse account, low-skilled individuals, who know they will gain from redistribution, increase consumption and reduce savings. Overall, MFF slightly increases physical capital accumulation with respect to the original FF system without significantly reducing labour supply incentives. Moreover, in the range of parameter values examined, MFF increases the social welfare with respect to both unfunded and pure funded schemes. For all these reasons, the MFF is preferable to both the FF and PAYG NDC schemes.

From a broader perspective, the introduction of MFF may help to reduce the burden of intragenerational redistribution. Collecting and investing a share of each worker's contribution in a State-managed fund, and at the time of retirement redistributing such resources equally among the corresponding population, helps to create a 'safety net' for low-income pensioners contributing to alleviate the taxation burden on future cohorts of workers.

It is worthwhile to mention that, in order to reduce the distortionary effect on labour supply arising when funded systems embody an intragenerational redistributive component, it could be useful to introduce a minimum number of hours worked, or a minimum level of effort, in order for the individual to be eligible for the redistribution.

Moreover, given the above discussion, even if the proposed MFF is able to reallocate resources among individuals, we are still in need of ensuring people against investment risk. If assets in which resources are invested perform poorly in fact, individuals face the risk of collecting inadequate pension benefits. In particular, in order

24 This kind of social welfare function is in accordance with the model of social welfare function considered in Chapter 17 of Heijdra (2003). 
to provide insurance against income uncertainty, the establishment of a proper regulation that imposes a banner on risky investments becomes of relevant importance. Actually, one can think, as it is happening in Chile, to create a Legal System that allows governments to provide transfers (up to a limit) to individuals who are not able to cover a minimum pension due, e.g., to poor investments performance.

To conclude, our model is complex enough to provide insights on the issues of intragenerational redistribution and intergenerational efficiency in a funded system where redistribution across individuals is possible, the labour supply is endogenous, and the workers differ in their productivity level, and at the same time, it is simple enough to be solvable in closed form.

Obviously, several extensions of this model are possible: some examples comprise dealing with uncertainty, introducing labour supply choices over multiple periods, including intertemporal non-separabilities in preferences, inserting endogeneity of health and human capital investments, and dealing with the potential unobservability of types and the resulting incentive compatibility. Nonetheless, for each of them, a separate study would be needed in order to show the possibility (or the impossibility) of obtaining a closed-form solution.

In the authors' opinion, a closed-form solution may be still obtained for two possible extensions. The first option is to introduce a third type of worker, unskilled, characterized by $h_{U}<h_{L}<h_{H}$, or even by $h_{U}=0$ in order to simplify the analysis. The second is to extend the model to a 'small' open economy for which some parameters become exogenously determined (Blanchard and Fischer, 1989). Conversely, a major change in the form of the utility function in equation (1) would likely imply the impossibility of obtaining a closed-form solution (a numerical approach could be used to find an approximate solution).

\section{References}

Aaron, H. (1966) The social insurance paradox. Canadian Journal of Economics and Political Science/Revue Canadienne de Economiques et Science Politique, 32(3): 371-374.

Barr, N., and Diamond, P. (2006) The economics of pensions. Oxford Review of Economic Policy, 22(1): 15-39.

Blake, D. (2006) Pension Economics. Chichester, West Sussex, England: John Wiley \& Sons.

Blanchard, O. J., and Fischer, S. (1989) Lectures on Macroeconomics. Cambridge, MA: MIT Press.

Bouzahzah, M., De la Croix, D., and Docquier, F. (2002) Policy reforms and growth in computable OLG economies. Journal of Economic Dynamics and Control, 26(12): 2093-2113.

Breyer, F. (1989) On the intergenerational Pareto efficiency of pay-as-you-go financed pension systems. Journal of Institutional and Theoretical Economics (JITE)/Zeitschrift für die Gesamte Staatswissenschaft, 145(4): 643-658.

Breyer, F., and Straub, M. (1993) Welfare effects of unfunded pension systems when labor supply is endogenous. Journal of Public Economics, 50(1): 77-91.

Diamond, P. A. (1965) National debt in a neoclassical growth model. The American Economic Review, 55(5): 1126-1150.

Disney, R. (1996) Can We Afford to Grow Older? A Perspective on the Economics of Aging. Cambridge, MA: MIT Press.

Disney, R. (1999) Notional Accounts as a Pension Reform Strategy: An Evaluation. Washington, DC: Social Protection, World Bank. 
Docquier, F., and Paddison, O. (2003) Social security benefit rules, growth and inequality. Journal of Macroeconomics, 25(1): 47-71.

Feldstein, M. (2005) Rethinking social insurance. The American Economic Review, 95(1): 1-24.

Feldstein, M., and Samwick, A. (1998) The transition path in privatizing social security. In Feldstein, M. (ed.), Privatizing Social Security. Chicago: University of Chicago Press, pp. 215-260.

Galor, O., and Weil, D. N. (1996) The gender gap, fertility, and growth. The American Economic Review, 86(3): 374-387.

Heijdra, B. J. (2003) Foundations of Modern Macroeconomics. Oxford, UK: Oxford University Press.

Holzmann, R., \& Palmer, E. E. (eds) (2006) Pension Reform: Issues and Prospects for NonFinancial Defined Contribution (NDC) Schemes. Washington, DC: World Bank Publications.

Homburg, S. (1990) The efficiency of unfunded pension schemes. Journal of Institutional and Theoretical Economics (JITE)/Zeitschrift für die Gesamte Staatswissenschaft, 146(4): 640-647.

Ignacio Conde-Ruiz, J., and Profeta, P. (2007) The redistributive design of social security systems. The Economic Journal, 117(520): 686-712.

Kotlikoff, L. J. (1996) Privatizing social security at home and abroad. The American Economic Review, 86(2): 368-372.

Kotlikoff, L. J. (1998) Simulating the privatization of social security in general equilibrium. In Feldstein, M. (ed.), Privatizing Social Security. Chicago: University of Chicago Press, pp. 265-311.

OECD (2014) OECD Pensions Outlook 2014. OECD Publishing. Available online at http://dx. doi.org/10.1787/9789264222687-en.

OECD (2015) Pensions at a Glance 2015: OECD and G20 Indicators. OECD Publishing. Available online at http://dx.doi.org/10.1787/pension_glance-2015-en.

Samuelson, P. A. (1958) An exact consumption-loan model of interest with or without the social contrivance of money. The Journal of Political Economy, 66(6): 467-482.

Samuelson, P. A. (1975) Optimum social security in a life-cycle growth model. International Economic Review, 16(3): 539-544.

Schwarz, A. M., Arias, O. S., Zviniene, A., Rudolph, H. P., Eckardt, S., Koettl, J., Immervoll, H., and Abels, M. (2014) The Inverting Pyramid: Pension Systems Facing Demographic Challenges in Europe and Central Asia. Washington, DC: World Bank.

Sinn, H. W. (2000) Why a funded pension system is needed and why it is not needed. International Tax and Public Finance, 7(4-5): 389-410.

Sommacal, A. (2006) Pension systems and intragenerational redistribution when labor supply is endogenous. Oxford Economic Papers, 58(3): 379-406.

Wen, X., Pammolli, F., and Gnecco, G. (2015) Labor supply and capital accumulation in an aging economy: when Beveridge Meets Bismarck. Proceedings of the 16th Annual Conference of Public Economic Theory (PET 15), University of Luxembourg, 2nd-4th July, 40 pages. Available online at https://editorialexpress.com/cgi-bin/conference/download.cgi?db_name $=$ PET15\&paper_id $=402$.

World Bank (2005) Notional Accounts: Notional Defined Contribution Plans as a Pension Reform Strategy. World Bank Pension Reform Primer Series. Washington, DC: World Bank.

\section{Appendix}

Proof of Proposition 1 [PAYG NDC]. Using equation (15), one obtains

$$
\Omega_{t+1}^{P A Y G N D C}=\frac{w_{t+1}^{P A Y G N D C} L_{t+1}^{P A Y G N D C}}{w_{t}^{P A Y G N D C}\left(1+\rho_{t+1}\right) L_{t}^{P A Y G N D C}} .
$$


This, combined with equations (7) and (8), provides:

$$
\frac{\Omega_{t+1}^{P A Y G N D C}}{R_{t+1}^{P A Y G N D C}}=\frac{(1-\alpha) L_{t+1}^{P A Y G N D C} k_{t+1}^{P A Y G N D C}}{w_{t}^{P A Y G N D C}\left(1+\rho_{t+1}\right) \alpha L_{t}^{P A Y G N D C}} .
$$

Then, using equations (5) and (14), one obtains:

$$
\begin{aligned}
l_{i, t}^{P A Y G N D C}= & (1-\tau) w_{t}^{P A Y G N D C} h_{i}+\frac{(1-\alpha) \tau h_{i} k_{t+1}^{P A Y G N D C}}{\alpha} \\
& \left(1+\rho_{t+1}\right) \frac{\lambda_{L} h_{L} l_{L, t+1}^{P A Y G N D C}+\lambda_{H} h_{H} l_{H, t+1}^{P A Y G D C}}{\lambda_{L} h_{L} l_{L, t}^{P A Y G N D C}+\lambda_{H} h_{H} l_{H, t}^{P A Y G D C}}
\end{aligned}
$$

Hence, when $i=L, H$, one has, respectively:

$$
\begin{aligned}
l_{L, t}^{P A Y G N D C}= & (1-\tau) w_{t}^{P A Y G N D C} h_{L}+\frac{(1-\alpha) \tau h_{L} k_{t+1}^{P A Y G N D C}}{\alpha} \\
& \left(1+\rho_{t+1}\right) \frac{\lambda_{L} h_{L} l_{L, t+1}^{P A Y G N D C}+\lambda_{H} h_{H} l_{H, t+1}^{P A Y N D C}}{\lambda_{L} h_{L} l_{L, t}^{P A Y G N D C}+\lambda_{H} h_{H} l_{H, t}^{P A Y G N D C}}, \\
l_{H, t}^{P A Y G N D C}= & (1-\tau) w_{t}^{P A Y G N D C} h_{H}+\frac{(1-\alpha) \tau h_{H} k_{t+1}^{P A Y G N D C}}{\alpha} \\
& \left(1+\rho_{t+1}\right) \frac{\lambda_{L} h_{L} l_{L, t+1}^{P A Y G N D C}+\lambda_{H} h_{H} l_{H, t+1}^{P A Y G N C}}{\lambda_{L} h_{L} l_{L, t}^{P A Y G N D C}+\lambda_{H} h_{H} l_{H, t}^{P A Y G N D C}} .
\end{aligned}
$$

Multiplying equations (A.4) and (A.5) by $h_{H}$ and $h_{L}$, respectively, and taking the difference, one obtains:

$$
l_{L, t}^{P A Y G N C} h_{H}-l_{H, t}^{P A Y G N D C} h_{L}=0,
$$

so

$$
\begin{aligned}
& l_{H, t}^{P A Y G N D C}=\frac{h_{H}}{h_{L}} l_{L, t}^{P A Y G N D C}, \\
& l_{H, t+1}^{P A Y G N D C}=\frac{h_{H}}{h_{L}} l_{L, t+1}^{P A Y G N D C} .
\end{aligned}
$$

Hence, equation (A.4) simplifies to:

$$
\begin{aligned}
l_{L, t}^{P A Y G N D C}= & (1-\alpha)(1-\tau) A h_{L}\left(k_{t}^{P A Y G N D C}\right)^{\alpha}+\frac{(1-\alpha) \tau h_{L} k_{t+1}^{P A Y G N D C}}{\alpha} \\
& \times\left(1+\rho_{t+1}\right) \frac{l_{L, t+1}^{P A Y G N D C}}{l_{L, t}^{P A Y N D D C}} .
\end{aligned}
$$

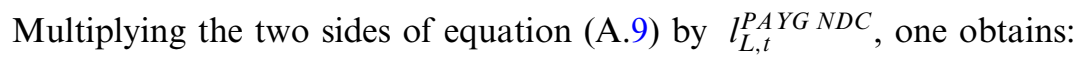

$$
\begin{aligned}
& \left(l_{L, t}^{P A Y G N D C}\right)^{2}-(1-\alpha)(1-\tau) A h_{L}\left(k_{t}^{P A Y G N D C}\right)^{\alpha} l_{L, t}^{P A Y G N D C}-\frac{(1-\alpha) \tau h_{L} k_{t+1}^{P A Y G N D C}}{\alpha} \\
& \left(1+\rho_{t+1}\right) l_{L, t+1}^{P A Y G N C}=0 .
\end{aligned}
$$


This is a second-order algebraic equation with discriminant $\Delta \geq 0$, whose only nonnegative solution is: 3

$$
\begin{aligned}
l_{L, t}^{P A Y G N D C}= & \frac{(1-\alpha)(1-\tau) A h_{L}\left(k_{t}^{P A Y G N D C}\right)^{\alpha}}{2} \\
& +\frac{\sqrt{\begin{array}{l}
(1-\alpha)^{2}(1-\tau)^{2} A^{2} h_{L}^{2}\left(k_{t}^{P A Y G N D C}\right)^{2 \alpha} \\
+\left(4 \tau(1-\alpha)\left(1+\rho_{t+1}\right) h_{L} / \alpha\right) k_{t+1}^{P A Y G N D C} l_{L, t+1}^{P A Y N D C}
\end{array}}}{2} .
\end{aligned}
$$

In the following, we also determine another recurrence satisfied by the capital per efficiency unit. To this aim, first we have to find expressions for the savings $s_{i, t}^{P A Y G N D C}$. Using equations (A.2) and (A.7), we can simplify the expression of $\Omega_{t+1}^{P A Y G N D C} / R_{t+1}^{P A Y G N D C}$ and determine the expression of $p_{i, t+1}^{P A Y G N D C} / R_{t+1}^{P A Y G N D C}$ as follows.

$$
\begin{gathered}
\frac{\Omega_{t+1}^{P A Y G N D C}}{R_{t+1}^{P A Y G N D C}}=\frac{k_{t+1}^{P A Y G N D C} l_{L, t+1}^{P A Y G N D C}}{A \alpha\left(k_{t}^{P A Y G N D C}\right)^{\alpha} l_{L, t}^{P A Y G N D C}}, \\
\frac{p_{i, t+1}^{P A Y G N D C}}{R_{t+1}^{P A Y G N D C}}=\tau(1-\alpha)\left(1+\rho_{t+1}\right) h_{i} l_{i, t} \frac{k_{t+1}^{P A Y G N D C} l_{L, t+1}^{P A Y G N C}}{\alpha l_{L, t}^{P A Y G N D C}} .
\end{gathered}
$$

Hence, using equations (4), (A.7), and (A.9), one gets the following expressions for $s_{L, t}^{P A Y G N D C}$ and $s_{H, t}^{P A Y G N D C}$ :

$$
\begin{aligned}
& s_{L, t}^{P A Y G N D C}=\frac{\beta(1-\tau)^{2} A^{2}(1-\alpha)^{2}\left(k_{t}^{P A Y G N D C}\right)^{2 \alpha} h_{L}^{2}}{2(1+\beta)} \\
& -\frac{\beta}{2(1+\beta)} \frac{(1-\alpha)^{2} \tau^{2} h_{L}^{2}\left(k_{t+1}^{P A Y G N D C}\right)^{2}}{\alpha^{2}}\left(1+\rho_{t+1}\right)^{2}\left(\frac{l_{L, t+1}^{P A Y G N D C}}{l_{L, t}^{P A Y G N D C}}\right)^{2} \\
& -\frac{\tau(1-\alpha)\left(1+\rho_{t+1}\right) h_{L} l_{L, t}^{P A Y G N D C}}{1+\beta} \frac{k_{t+1}^{P A Y G N D C}}{\alpha} \frac{l_{L, t+1}^{P A Y G N D C}}{l_{L, t}^{P A Y G N D C}}, \\
& s_{H, t}^{P A Y G N D C}=\frac{\beta(1-\tau)^{2} A^{2}(1-\alpha)^{2}\left(k_{t}^{P A Y G N D C}\right)^{2 \alpha} h_{H}^{2}}{2(1+\beta)} \\
& -\frac{\beta}{2(1+\beta)} \frac{(1-\alpha)^{2} \tau^{2} h_{H}^{2}\left(k_{t+1}^{P A Y G N D C}\right)^{2}}{\alpha^{2}}\left(1+\rho_{t+1}\right)^{2}\left(\frac{l_{L, t+1}^{P A Y G N C}}{l_{L, t}^{P A Y G N D C}}\right)^{2} \\
& -\frac{\tau(1-\alpha)\left(1+\rho_{t+1}\right) h_{H}^{2} l_{L, t}^{P A Y G N D C}}{h_{L}(1+\beta)} \frac{k_{t+1}^{P A Y G N D C}}{\alpha} \frac{l_{L, t+1}^{P A Y G N D C}}{l_{L, t}^{P A Y N D C}} .
\end{aligned}
$$


Combining equations (A.14) and (A.15), one gets:

$$
\begin{aligned}
K_{t+1}^{P A Y G N D C}= & \frac{N_{t}}{1+\beta}\left[\beta(1-\tau)^{2} A^{2}(1-\alpha)^{2}\left(k_{t}^{P A Y G N D C}\right)^{2 \alpha} \frac{\lambda_{L} h_{L}^{2}+\lambda_{H} h_{H}^{2}}{2}\right. \\
& -\frac{\beta}{2} \frac{(1-\alpha)^{2} \tau^{2}\left(k_{t+1}^{P A Y G N D C}\right)^{2}}{\alpha^{2}}\left(1+\rho_{t+1}\right)^{2}\left(\frac{l_{L, t+1}^{P A Y G N C}}{l_{L, t}^{P A Y G N D C}}\right)^{2}\left(\lambda_{L} h_{L}^{2}+\lambda_{H} h_{H}^{2}\right) \\
& \left.-\tau(1-\alpha)\left(1+\rho_{t+1}\right) \frac{k_{t+1}^{P A Y G N D C}}{\alpha} l_{L, t+1}^{P A Y G} N \frac{\lambda_{L} h_{L}^{2}+\lambda_{H} h_{H}^{2}}{h_{L}}\right] .
\end{aligned}
$$

Then, one obtains:

$$
\begin{aligned}
& L_{t+1}^{P A Y G N D C}=N_{t}\left(1+\rho_{t+1}\right) \frac{\lambda_{L} h_{L}^{2}+\lambda_{H} h_{H}^{2}}{h_{L}} l_{L, t+1}^{P A Y G N D C}, \\
k_{t+1}^{P A Y G N D C}= & \frac{1}{2(1+\beta)\left(1+\rho_{t+1}\right) l_{L, t+1}^{P A Y G N D C}}\left[A^{2} \beta(1-\alpha)^{2}(1-\tau)^{2} h_{L}\left(k_{t}^{P A Y G N D C}\right)^{2 \alpha} .\right. \\
& -\frac{\beta \tau^{2}(1-\alpha)^{2}\left(1+\rho_{t+1}\right)^{2} h_{L}}{\alpha^{2}}\left(\frac{l_{L, t+1}^{P A Y G N D C}}{l_{L, t}^{P A Y G N D C}}\right)^{2}\left(k_{t+1}^{P A Y G N D C}\right)^{2} \\
& \left.-\frac{2 \tau(1-\alpha)\left(1+\rho_{t+1}\right) k_{t+1}^{P A Y G N D C}}{\alpha} l_{L, t+1}^{P A Y G N D C}\right] .
\end{aligned}
$$

In the following, we also show how one can express $K_{t+1}^{P A Y G N D C}$ as a function of $k_{t}^{P A Y G N D C}$. Starting from equation (A.10), one gets:

$$
l_{L, t+1}^{P A Y G N D C}=\frac{l_{L, t}^{P A Y G N D C}\left(l_{L, t}^{P A Y G N D C}-(1-\alpha)(1-\tau) A h_{L}\left(k_{t}^{P A Y G N D C}\right)^{\alpha}\right)}{\left((1-\alpha) \tau h_{L} k_{t+1}^{P A Y G N D C} / \alpha\right)\left(1+\rho_{t+1}\right)}
$$

which requires:

$$
l_{L, t}^{P A Y G N D C} \geq(1-\alpha)(1-\tau) A h_{L}\left(k_{t}^{P A Y G N D C}\right)^{\alpha}
$$

to guarantee the non-negativity of $l_{L, t+1}^{P A Y G N D C}$. Then, using also equation (A.18), one 
obtains:

$$
\begin{aligned}
& 2(1+\beta)\left(1+\rho_{t+1}\right) k_{t+1}^{P A Y G N D C} \frac{l_{L, t}^{P A Y G N D C}\left(l_{L, t}^{P A Y G N D C}-(1-\alpha)(1-\tau) A h_{L}\left(k_{t}^{P A Y G N D C}\right)^{\alpha}\right)}{\left((1-\alpha) \tau h_{L} k_{t+1}^{P A Y G N D C} / \alpha\right)\left(1+\rho_{t+1}\right)} \\
& =A^{2} \beta(1-\alpha)^{2}(1-\tau)^{2} h_{L}\left(k_{t}^{P A Y G N D C}\right)^{2 \alpha} \\
& -\frac{\beta \tau^{2}(1-\alpha)^{2}\left(1+\rho_{t+1}\right)^{2} h_{L}}{\alpha^{2}} \\
& \underline{\left(l_{L, t}^{\text {PAY NDC }}\right)^{2}\left(l_{L, t}^{\text {PAYG NDC }}-(1-\alpha)(1-\tau) A h_{L}\left(k_{t}^{P A Y G N D C}\right)^{\alpha}\right)^{2}} \\
& \times \frac{\left((1-\alpha)^{2} \tau^{2} h_{L}^{2}\left(k_{t+1}^{P A Y G N D C}\right)^{2} / \alpha^{2}\right)\left(1+\rho_{t+1}\right)^{2}}{\left(l_{L, t}^{\text {PAYG NDC }}\right)^{2}}\left(k_{t+1}^{\text {PAYG NDC }}\right)^{2} \\
& -\frac{2 \tau(1-\alpha)\left(1+\rho_{t+1}\right) k_{t+1}^{P A Y G N D C}}{\alpha} \\
& \times \frac{l_{L, t}^{P A Y G N D C}\left(l_{L, t}^{P A Y G N D C}-(1-\alpha)(1-\tau) A h_{L}\left(k_{t}^{P A Y G N D C}\right)^{\alpha}\right)}{\left((1-\alpha) \tau h_{L} k_{t+1}^{P A Y G N D C} / \alpha\right)\left(1+\rho_{t+1}\right)} .
\end{aligned}
$$

Hence,

$$
\begin{aligned}
\frac{2 \alpha(1+\beta) l_{L, t}^{P A Y G N D C}\left(l_{L, t}^{P A Y G N D C}-(1-\alpha)(1-\tau) A h_{L}\left(k_{t}^{P A Y G N D C}\right)^{\alpha}\right)}{(1-\alpha) \tau h_{L}} \\
=A^{2} \beta(1-\alpha)^{2}(1-\tau)^{2} h_{L}\left(k_{t}^{P A Y G N D C}\right)^{2 \alpha} \\
\quad-\frac{\beta\left(l_{L, t}^{P A Y G N D C}-(1-\alpha)(1-\tau) A h_{L}\left(k_{t}^{P A Y G N D C}\right)^{\alpha}\right)^{2}}{h_{L}} \\
-\frac{2 l_{L, t}^{P A Y G N D C}\left(l_{L, t}^{P A Y G N D C}-(1-\alpha)(1-\tau) A h_{L}\left(k_{t}^{P A Y G N D C}\right)^{\alpha}\right)}{h_{L}} .
\end{aligned}
$$

After some simplifications, (A.22) reduces to:

$$
\frac{2 \alpha(1+\beta)+\tau(1-\alpha)(2+\beta)}{(1-\alpha) \tau}=\beta \frac{(1-\alpha)(1-\tau) A h_{L}\left(k_{t}^{P A Y G N D C}\right)^{\alpha}}{l_{L, t}^{P A Y G N D C}-(1-\alpha)(1-\tau) A h_{L}\left(k_{t}^{P A Y G N D C}\right)^{\alpha}} .
$$

Concluding, one can express $l_{L, t}^{P A Y N D C}$ as a function of $k_{t}^{P A Y G N D C}$ as follows: $l_{L, t}^{P A Y G N D C}=\frac{[\beta \tau(1-\alpha)+2 \alpha(1+\beta)+\tau(1-\alpha)(2+\beta)](1-\alpha)(1-\tau) A h_{L}}{2 \alpha(1+\beta)+\tau(1-\alpha)(2+\beta)}\left(k_{t}^{P A Y G N D C}\right)^{\alpha}$,

which also satisfies equation (A.20). Then, using equation (A.7), one obtains:

$l_{H, t}^{P A Y G N D C}=\frac{[\beta \tau(1-\alpha)+2 \alpha(1+\beta)+\tau(1-\alpha)(2+\beta)](1-\alpha)(1-\tau) A h_{H}}{2 \alpha(1+\beta)+\tau(1-\alpha)(2+\beta)}\left(k_{t}^{P A Y G N D C}\right)^{\alpha}$. 
From equation (A.24), one gets:

$$
\frac{l_{L, t+1}^{P A Y N D C}}{l_{L, t}^{P A Y N D C}}=\frac{\left(k_{t+1}^{P A Y G N D C}\right)^{\alpha}}{\left(k_{t}^{P A Y G N D C}\right)^{\alpha}}
$$

which, combined with (A.9) and (A.24), provides:

$$
\begin{aligned}
& \frac{[\beta \tau(1-\alpha)+2 \alpha(1+\beta)+\tau(1-\alpha)(2+\beta)](1-\alpha)(1-\tau) A h_{L}}{2 \alpha(1+\beta)+\tau(1-\alpha)(2+\beta)}\left(k_{t}^{P A Y G N D C}\right)^{\alpha} \\
& \quad=(1-\alpha)(1-\tau) A h_{L}\left(k_{t}^{P A Y G N D C}\right)^{\alpha}+\frac{(1-\alpha) \tau h_{L} k_{t+1}^{P A Y G N D C}}{\alpha}\left(1+\rho_{t+1}\right) \frac{\left(k_{t+1}^{P A Y G N D C}\right)^{\alpha}}{\left(k_{t}^{P A Y G N D C}\right)^{\alpha}}
\end{aligned}
$$

Then, after some simplifications, one obtains:

$$
k_{t+1}^{P A Y G N D C}=\left[\frac{A \alpha \beta(1-\alpha)(1-\tau)}{\left[2 \alpha(1+\beta)+\tau(1-\alpha)(2+\beta)\left(1+\rho_{t+1}\right)\right.}\right]^{1 / 1+\alpha}\left(k_{t}^{P A Y G N D C}\right)^{2 \alpha / 1+\alpha},
$$

which is the desired recursive formula.

When $\rho_{t}=\rho$ for all $t$, the steady-state expression of the capital per efficiency unit is trivially obtained equating $k_{t+1}^{P A Y G N D C}$ and $k_{t}^{P A Y G N D C}$, whereas the steady-state expressions for the individual labour supply choices, for the pension, and for the capital per person are obtained using (A.24), (A.7), (14), (15), (7), and (11).

Summarizing the analysis above, for the PAYG NDC case one obtains equations (25)-(30).

Proof of Proposition 2 [MFF]. For simplicity, we start reporting the steps required for the case $\lambda_{L}=\lambda_{H}=1 / 2$. Combining equations (5) and (19)-(22), one obtains:

$$
l_{i, t}^{M F F}=\left(1-\frac{b \tau}{2}\right) w_{t}^{M F F} h_{i}
$$

which implies:

$$
l_{H, t}^{M F F}=\frac{h_{H}}{h_{L}} l_{L, t}^{M F F}
$$

Now, using equation (A.29), we notice that:

$$
\begin{aligned}
& (1-b) \tau w_{t}^{M F F} h_{L} l_{L, t}^{M F F}+\sum_{i=L, H} \frac{b \tau w_{t}^{M F F} h_{i} l_{i, t}^{M F F}}{2} \\
& =\tau\left[\left(1-\frac{b}{2}\right) h_{L}^{2}+\frac{b}{2} h_{H}^{2}\right]\left(1-\frac{b \tau}{2}\right)\left(w_{t}^{M F F}\right)^{2},
\end{aligned}
$$


and similarly,

$$
\begin{aligned}
& (1-b) \tau w_{t}^{M F F} h_{H} l_{H, t}^{M F F}+\sum_{i=L, H} \frac{b \tau w_{t}^{M F F} h_{i} l_{i, t}^{M F F}}{2} \\
& =\tau\left[\left(1-\frac{b}{2}\right) h_{H}^{2}+\frac{b}{2} h_{L}^{2}\right]\left(1-\frac{b \tau}{2}\right)\left(w_{t}^{M F F}\right)^{2} .
\end{aligned}
$$

These, combined with equations (4) and (5), provide:

$$
s_{L, t}^{M F F}=\frac{1-(b \tau / 2)}{1+\beta}\left[\left(\frac{2 \beta+b \tau(2+\beta)}{4}-\tau(1+\beta)\right) h_{L}^{2}-\frac{b \tau}{2} h_{H}^{2}\right]\left(w_{t}^{M F F}\right)^{2},
$$

and

$$
s_{H, t}^{M F F}=\frac{1-(b \tau / 2)}{1+\beta}\left[\left(\frac{2 \beta+b \tau(2+\beta)}{4}-\tau(1+\beta)\right) h_{H}^{2}-\frac{b \tau}{2} h_{L}^{2}\right]\left(w_{t}^{M F F}\right)^{2} .
$$

Then, using equation (24) and the equations above, one gets:

$$
\begin{gathered}
K_{t+1}^{M F F}=\frac{N_{t} \beta(1-(b \tau / 2))(1+(b \tau / 2))}{4(1+\beta)}\left(h_{L}^{2}+h_{H}^{2}\right)\left(w_{t}^{M F F}\right)^{2}, \\
L_{t+1}^{M F F}=\frac{N_{t+1}}{2}\left(1-\frac{b \tau}{2}\right) w_{t+1}^{M F F}\left(h_{L}^{2}+h_{H}^{2}\right) \\
k_{t+1}^{M F F}=\left[\frac{\beta(1+(b \tau / 2)) A(1-\alpha)}{2(1+\beta)\left(1+\rho_{t+1}\right)}\right]^{1 / 1+\alpha}\left(k_{t}^{M F F}\right)^{2 \alpha / 1+\alpha},
\end{gathered}
$$

which is the desired recursive formula.

When $\rho_{t}=\rho$ for all $t$, the steady-state expression for the capital per efficiency unit is trivially obtained equating $k_{t+1}^{M F F}$ and $k_{t}^{M F F}$, whereas the steady-state expressions for the individual labour supply choices, for the two components of the pension, and for the capital per worker are obtained using (A.29), (7), (21), (22), (8), and (11).

Summarizing the analysis above, for the MFF case with $\lambda_{L}=\lambda_{H}=1 / 2$ one obtains equations (35)-(42) specialized to this case.

In the general case $\lambda_{L} \neq \lambda_{H} \neq 1 / 2$, equations (A.29), (A.30), (A.35), (A.36), (A.37) above are modified as follows:

$$
\begin{aligned}
& l_{i, t}^{M F F}=\left(1-b \tau\left(1-\lambda_{i}\right)\right) h_{i} . \\
& l_{H, t}^{M F F}=\frac{\left(1-b \tau \lambda_{L}\right) h_{H}}{\left(1-b \tau \lambda_{H}\right) h_{L}} l_{L, t}^{M F F} . \\
& K_{t+1}^{M F F}=\frac{N_{t}\left[\lambda_{L} h_{L}^{2}+\lambda_{H} h_{H}^{2}-b^{2} \tau^{2}\left(\lambda_{L} h_{L}^{2}+\lambda_{H} h_{H}^{2}\right) \lambda_{L} \lambda_{H}\right]}{2(1+\beta)\left[\lambda_{L} h_{L}^{2}+\lambda_{H} h_{H}^{2}-b \tau\left(h_{L}^{2}+h_{H}^{2}\right) \lambda_{L} \lambda_{H}\right]} \lambda_{L} h_{L}^{2} \\
& +\lambda_{H} h_{H}^{2}-b \tau \lambda_{L} \lambda_{H}\left(h_{L}^{2}+h_{H}^{2}\right)\left(w_{t+1}^{M F F}\right)^{2}, \\
& L_{t+1}^{M F F}=N_{t+1}\left[\lambda_{L} h_{L}^{2}+\lambda_{H} h_{H}^{2}-b \tau \lambda_{L} \lambda_{H}\left(h_{L}^{2}+h_{H}^{2}\right)\right] w_{t+1}^{M F F}, \\
& k_{t+1}^{M F F}=\left[\frac{A \beta\left[\lambda_{L} h_{L}^{2}+\lambda_{H} h_{H}^{2}-b^{2} \tau^{2}\left(\lambda_{H} h_{L}^{2}+\lambda_{L} h_{H}^{2}\right) \lambda_{L} \lambda_{H}\right](1-\alpha)}{2(1+\beta)\left(1+\rho_{t+1}\right)\left[\lambda_{L} h_{L}^{2}+\lambda_{H} h_{H}^{2}-b \tau\left(h_{L}^{2}+h_{H}^{2}\right) \lambda_{L} \lambda_{H}\right]}\right]^{1 / 1+\alpha}\left(k_{t}^{M F F}\right)^{2 \alpha / 1+\alpha} .
\end{aligned}
$$


Summarizing, for the MFF case with $\lambda_{L} \neq \lambda_{H} \neq 1 / 2$ one obtains equations (35)-(42) expressed for this general case.

\section{Labour supply (extension of Section 4.1 to $\rho \neq 0$ )}

In this part of the Appendix, we remove the assumption of a non-growing population, i.e., we allow $\rho$ to be different from zero. For simplicity, we refer only to its effect on the labour supply choice. Keeping in mind the negative effect on labour supply induced by the presence of a tax on labour in both PAYG NDC and MFF, we now conduct a brief analysis on the effect of an increase in the tax rate $\tau$ when the population is either increasing or ageing.

In Figure A1, we present the labour supply distortion suffered by high-skilled workers as a result of an increase in the tax rate $\tau$ when $\rho$ is allowed to vary. ${ }^{25}$ Moreover, since a variation in the tax rate does not affect the individual's behaviour in a pure FF system, we present the PAYG NDC and the MFF cases only.

As one might expect, in a PAYG NDC system, irrespective of the proportion of high- and low-skilled workers in the economy, when taxes are higher, individuals are more willing to work less. Provided that, the amount of labour supplied by the single individual is higher in an ageing economy. As $\rho$ decreases in fact, the capital per efficiency unit increases and so does the worker's wage. From higher labour earnings, it follows a higher incentive to work.

When analysing the possible reduction in labour supply coming from an increase in $\tau$ in a context where $\rho$ is different from zero, we have to take into account that the composition of population matters. From Section 4.1, in fact we notice that the distortion of labour supply for high-skilled workers is higher when the fraction of low-
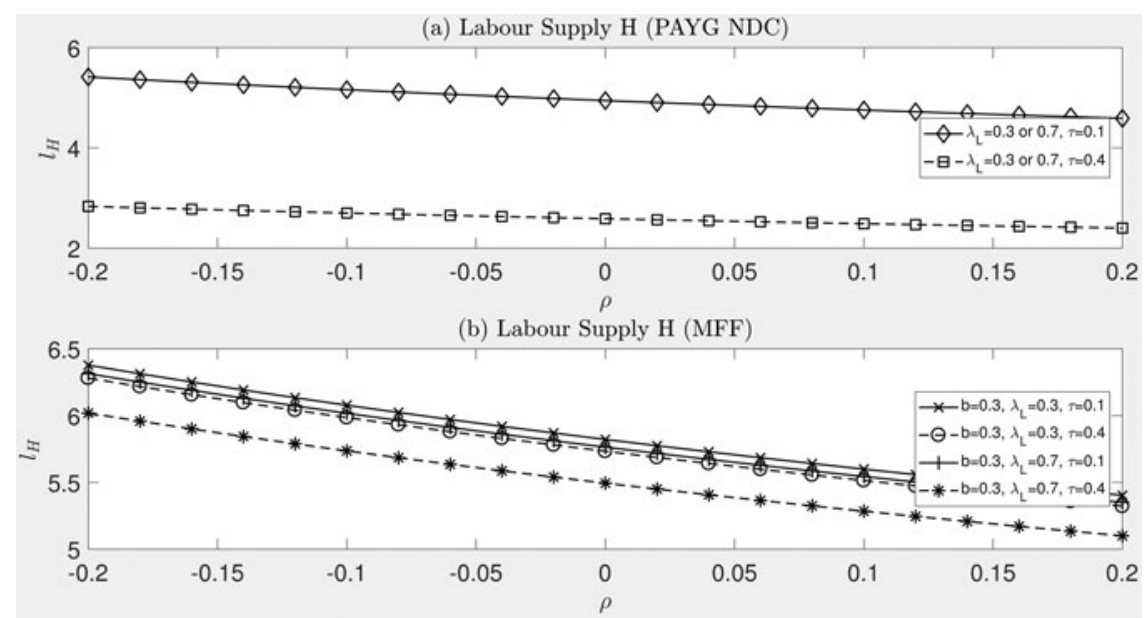

Figure A1. Labour supply distortion for high- and low-skilled workers when $\rho \neq 0$.

Source: Authors' calculations.

25 The first part of the Appendix has shown that the behaviour of low-skilled workers is similar to the one of high-skilled individuals. 
skilled individuals is the largest. Other than that, we can follow the reasoning applied for the PAYG NDC case. Even in a MFF, as $\rho$ decreases, there exists a higher incentive to work.

\section{Partial derivatives at the non-trivial steady states}

In this final part of the Appendix, we report, for each of the three pension systems, the signs of the partial derivatives (with respect to the most significant parameters) of several quantities of interest at the respective non-trivial steady state of the pension system. Tables A1-A3 refer, respectively, to the PAYG NDC, FF, and MFF systems. As an example, to construct Table A3, first we have fixed the parameters $\alpha, \beta, A, h_{H}$ to $\alpha=0.29, \beta=0.29, A=8$, and $h_{H}=0.9$, then we have varied the other parameters $b, \tau$, $\rho, \lambda_{L}, h_{L}$ in the following ranges: $b \in[0,0.3], \tau \in[0.22,0.36], \rho \in[-0.2,0.2], \lambda_{L} \in[0$, $0.99]$, and $h_{L} \in\left[0.1 h_{H}, 0.9 h_{H}\right]$. Finally, partial derivatives with respect to these last five parameters have been evaluated numerically on a uniform grid defined on the

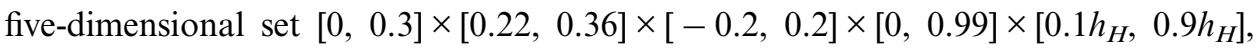
and containing a total of $6^{5}=7,776$ points. A similar construction (with fourdimensional sets, being the parameter $b$ missing) has been used to construct Tables A1 and A2. The three tables report, in each entry, the sign of the partial derivative of the function associated with its row with respect to the variable associated with

Table A1. Signs of the partial derivatives of several functions at the non-trivial PAYG NDC steady state

\begin{tabular}{|c|c|c|c|c|}
\hline \multirow[b]{2}{*}{ Function } & \multicolumn{4}{|c|}{ Sign of the partial derivative with respect to the parameter } \\
\hline & $\tau$ & $\rho$ & $\lambda_{L}$ & $h_{L}$ \\
\hline$k^{P A Y G N D C}$ & - & 0 & 0 & - \\
\hline$K_{t}^{P A Y G N D C} / N_{t}$ & - & 0 & - & \pm \\
\hline$l_{L}^{P A Y G N D C}$ & - & 0 & 0 & + \\
\hline$l_{H}^{P A Y G N D C}$ & - & 0 & 0 & - \\
\hline${ }_{w}^{P A Y G N D C}$ & - & 0 & 0 & - \\
\hline$R^{P A Y G N D C}$ & + & 0 & 0 & + \\
\hline$p_{L}^{P A Y G N D C}$ & \pm & 0 & 0 & + \\
\hline$p_{H}^{P_{A} Y G N D C}$ & \pm & 0 & 0 & + \\
\hline$p^{P A Y G N D C}$ & \pm & 0 & - & + \\
\hline$s_{L}^{P A Y G N D C}$ & - & 0 & 0 & + \\
\hline$s_{H}^{P_{A} A Y G N D C}$ & - & 0 & 0 & - \\
\hline 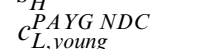 & - & 0 & 0 & + \\
\hline $\begin{array}{l}L, y \text { oung } \\
c_{L, o l d}^{P A Y} \text { NDC }\end{array}$ & - & 0 & 0 & + \\
\hline $\begin{array}{l}L, \text { old } N D D C \\
c_{H, \text { Young }}^{P A}\end{array}$ & - & 0 & 0 & - \\
\hline$c_{H \text { old }}^{P A Y N D C}$ & - & 0 & 0 & + \\
\hline$U_{L}^{P}$ PAYG NDC & - & 0 & 0 & + \\
\hline$U_{H}^{P A Y G G N D C}$ & - & 0 & 0 & - \\
\hline$U^{H A Y G N D C}$ & - & 0 & - & \pm \\
\hline
\end{tabular}

Source: Authors' calculations. 
Table A2. Signs of the partial derivatives of several functions at the non-trivial FF steady state

\begin{tabular}{|c|c|c|c|c|}
\hline \multirow[b]{2}{*}{ Function } & \multicolumn{4}{|c|}{ Sign of the partial derivative with respect to the parameter } \\
\hline & $\tau$ & $\rho$ & $\lambda_{L}$ & $h_{L}$ \\
\hline$k^{F F}$ & 0 & - & 0 & 0 \\
\hline$K_{t}^{F F} / N_{t}$ & 0 & - & - & $\geq 0$ \\
\hline$l_{L}^{F F}$ & 0 & - & 0 & + \\
\hline$l_{H}^{F F}$ & 0 & - & 0 & 0 \\
\hline$w^{F F}$ & 0 & - & 0 & 0 \\
\hline$R^{F F}$ & 0 & + & 0 & 0 \\
\hline$p_{L}^{F F}$ & + & + & 0 & + \\
\hline$p_{H}^{F F}$ & + & + & 0 & 0 \\
\hline$p^{F F}$ & + & + & - & $\geq 0$ \\
\hline$s_{I}^{F F}$ & - & \pm & 0 & \pm \\
\hline$s_{H}^{L F}$ & - & \pm & 0 & $\overline{0}$ \\
\hline $\begin{array}{l}{ }^{H} H \\
c_{L}^{F F}\end{array}$ & 0 & - & 0 & + \\
\hline $\begin{array}{l}\text { L,young } \\
c_{L \text { old }}^{F F}\end{array}$ & \pm & + & 0 & + \\
\hline$c_{H, \text { young }}^{F F}$ & 0 & - & 0 & 0 \\
\hline$c_{H, \text { old }}^{H, F \text { oung }}$ & \pm & + & 0 & 0 \\
\hline$U_{L}^{F F}$ & \pm & - & 0 & + \\
\hline$U_{H}^{F F}$ & \pm & - & 0 & 0 \\
\hline$U^{H}$ & \pm & - & - & $\geq 0$ \\
\hline
\end{tabular}

Source: Authors' calculations.

Table A3. Signs of the partial derivatives of several functions at the non-trivial MFF steady state

\begin{tabular}{|c|c|c|c|c|c|}
\hline \multirow[b]{2}{*}{ Function } & \multicolumn{5}{|c|}{ Sign of the partial derivative with respect to the parameter } \\
\hline & $b$ & $\tau$ & $\rho$ & $\lambda_{L}$ & $h_{L}$ \\
\hline$k^{M F F}$ & $\geq 0$ & $\geq 0$ & - & \pm & \pm \\
\hline$K_{t}^{M F F} / N_{t}$ & $\geq 0$ & $\geq 0$ & - & \pm & $\geq 0$ \\
\hline$l_{L}^{M F F}$ & \pm & \pm & - & \pm & + \\
\hline$l_{H}^{M F F}$ & $\leq 0$ & $\leq 0$ & - & $\leq 0$ & \pm \\
\hline$w^{M F F}$ & $\geq 0$ & $\geq 0$ & - & \pm & \pm \\
\hline$R^{M F F}$ & $\leq 0$ & $\leq 0$ & + & \pm & \pm \\
\hline$p_{L}^{M F F}$ & \pm & + & + & \pm & + \\
\hline$p_{H}^{M F F}$ & $\leq 0$ & + & + & \pm & $\geq 0$ \\
\hline$p^{M F F}$ & $\leq 0$ & + & + & \pm & $\geq 0$ \\
\hline$s_{L}^{M F F}$ & \pm & - & \pm & \pm & \pm \\
\hline$s_{H}^{M F F}$ & $\geq 0$ & - & \pm & \pm & \pm \\
\hline$c_{L, \text { voung }}^{M}$ & + & $\geq 0$ & - & \pm & + \\
\hline$c_{L, \text { old }}^{\text {MFong }}$ & \pm & \pm & + & \pm & + \\
\hline$c_{H, \text { voung }}^{M F P}$ & \pm & \pm & - & \pm & \pm \\
\hline$c_{H_{i} \text { old }}^{M F}$ & \pm & \pm & + & \pm & $\geq 0$ \\
\hline$U_{L}^{M F F}$ & + & \pm & - & \pm & + \\
\hline$U_{H}^{M F F}$ & \pm & \pm & - & \pm & \pm \\
\hline$U^{M F F}$ & $\geq 0$ & \pm & + & \pm & $\geq 0$ \\
\hline
\end{tabular}

Source: Authors' calculations. 
its column. The symbol reported in each entry is, respectively, $+,-, \geq 0, \leq 0$, or 0 if that partial derivative is, respectively, positive, negative, non-negative, non-positive, or zero on the whole uniform grid, otherwise it is \pm if the partial derivative changes sign on that grid. It is worth noting from Table A3 that, for the MFF pension system, the partial derivative of the utility per worker $U^{M F F}$ with respect to the parameter $b$ turns out to be non-negative on the whole grid, which is coherent with what reported at the end of Section 4.3 about the social welfare-improving effect of the proposed MFF pension system. 